Article

\title{
Application of earth observation data and Google Earth Engine for monitoring coral reef exposure to en- vironmental stressors
}

\author{
Michael J. Williamson ${ }^{1,2 *}$, Emma J. Tebbs ${ }^{1}$, Henry J. Thompson ${ }^{1}$, Terence P. Dawson ${ }^{1}$, Catherine E. \\ I. Head ${ }^{2,3}$ and David M. P. Jacoby ${ }^{2}$ \\ 1 Department of Geography, Bush House (NE), King's College London, 40 Aldwych, \\ London WC2B 4BG \\ 2 Institute of Zoology, Zoological Society of London Outer Circle, Regent's Park, London, \\ NW1 4RY, UK \\ 3 Department of Zoology, University of Oxford, Zoology Research and Administration \\ Building, 11a Mansfield Road, Oxford, OX1 3SZ, UK \\ * Correspondence: michael.williamson@kcl.ac.uk
}

\begin{abstract}
Coral reefs are critical ecosystems globally for marine fauna, biodiversity and through the services they provide to humanity. However, they are significantly threatened by anthropogenic stressors, such as climate change. By combining 9 environmental variables and ecological and health-based thresholds obtained from the available literature, we develop, using fuzzy logic (discontinuous functions), a Coral Reef Stress Exposure Index (CRSEI) for remotely monitoring coral reef exposure to environmental stressors. Our approach capitalises on the abundance of readily available satellite Earth Observation (EO) data available in the Google Earth Engine (GEE) cloud-based geospatial processing platform. CRSEI values from 3157 distinct reefs were generated and mapped across $12 \mathrm{im}$ portant coral reef ecosystem regions. Quantitative analyses indicated that the index detected significant temporal differences in stress and was, therefore, able to capture historic change at a global scale. We also applied the CRSEI to three casestudy reef ecosystems, previously well-monitored for stress and disturbance using other methods. PCA analysis indicated that depth, current, sea surface temperature (SST) and SST anomaly accounted for the greatest contribution to the variance in stress in these three regions. The CRSEI corroborated temporal and spatial differences in stress exposure from known disturbances within these reference regions, in addition to identifying the potential drivers of inter- and intraregion differences in stress, namely depth, degree heating weeks and SST anomaly. We discuss how the index can be further improved in future with site-specific thresholds for each stress variable, and the incorporation of additional variables not currently available in GEE. This index provides an open access tool, built around a free and powerful processing platform, that has broad potential to assist in the regular monitoring of our increasingly imperilled coral reef ecosystems, and, in particular, those that are remote or inaccessible.
\end{abstract}

Keywords: bleaching; coral reef; environmental stress; Google Earth Engine; monitoring; remote sensing; satellite 


\section{Introduction}

Coral reefs are important ecosystems for a wide range of marine fauna and biodiversity [1-3], as well as providing numerous ecosystem services, such as protecting coastlines from storm surges, raw materials for medicines, seafood products and tourism [4-6]. However, they are facing unprecedented pressures from an increasing diversity, frequency, and scale of threats [7-10]. Over the past 20 years there has been a significant increase in disease, tropical cyclones and bleaching events in coral reef ecosystems [11-14], resulting in a significant decline in coral cover across the world's reef systems [15-17]. Monitoring is a fundamental part of ecosystem conservation and management [18]. As such, regular assessment of stressors and monitoring declines, in both space and time, has become increasingly important for coral reefs [19]. This is due to the challenges of preserving conservation goals while maintaining their importance as a resource for human populations in the face of growing impacts from climate change [20]. In addition, their value and vulnerability make coral reefs appropriate sentinels for global climate change [21]. Thus, monitoring reef ecosystems is also important for assessing how the marine environment is responding to anthropogenic induced changes, such as ocean warming, coastal construction, and pollution. To facilitate this endeavour, in recent years there has been an increased emphasis on the use of satellite remote sensing to monitor coral reef ecosystems, as satellites can provide greater coverage and take less time than traditional field surveys, and with ever increasing accuracy $[19,22]$.

Loss of coral cover from disease or bleaching can be triggered by multiple different stressors which may directly impact coral reef health or influence how reef ecosystems are affected by, or recover from, other disturbances [23-25]. The impact of sea surface temperature (SST) on coral reef populations is well established [26-28], as is the influence of depth $[29,30]$. However, the impact of other variables, such as salinity and current, and the role they play in determining localised reef stress, are less well understood and may vary depending on the site, species composition and population size of a coral reef [29,31,32]. Although certain variables may be significant stressors to coral reefs on their own, many are compounded or amplified, in synthesis with others [25,33,34]. However, few studies have investigated how multiple variables can combine to impact stress on coral reef ecosystems. A more holistic approach to coral reef stress assessment is important to identify not only those reefs that are most under threat, but also those that are limited in their ability to recover from disturbance events.

As stressors in ecosystem health may be multifactorial [35-38], indices are frequently used to aggregate a suite of variables known to have either a positive or negative influence on health [39-41]. These indices can give a robust indication of environmental status and have been used to assess several different ecosystem types, such as coastal $[41,42]$, riverine $[39,40]$ and oceanic $[20,43]$ habitats. Incorporating a range of indicators into monitoring programmes can also help identify the specific variables that are causing impacts, be it at local, regional or global scales [39]. The diagnostic capabilities of such scoring systems can then be used to guide management programs for damaged ecosystems $[39,41]$. For an index to be a useful tool for environmental management however, it should be quantifiable and reproducible. In addition, to make the index more accessible and useful as a tool for conservation organisations and non-governmental organisations (NGOs), which may not have 
the funds for regular surveys or expensive monitoring programs, the index should be developed from free and open-source data where possible.

Satellite remote sensing has become an important tool for marine science in the past 30 years and is increasingly playing a role in conservation and management of marine fauna, for example defining Marine Protected Areas and monitoring change of important habitats, such as mangroves, coastal zones, and coral reefs [44-47]. As such there are now several studies that utilise remotely sensed environmental data to assess the health and stress on coral reef ecosystems. For example, U.S. National Oceanic and Atmospheric Administration's (NOAA) Coral Reef Watch (https://coralreefwatch.noaa.gov/satellite/index.php) uses satellite remotely sensed data such as SST and Degree Heating Weeks (DHW) to monitor coral bleaching events [48,49]. However, most of these studies primarily utilise just one or two environmental variables, and primarily focus on thermal stress [19]. Some studies however, have started to integrate multiple environmental variables into their analyses [e.g., Maina et al. [50]] but often don't allow investigations over time. In addition, they may use products that are not free or open or develop their own products as part of their analyses, which may be out of the budgets and technical expertise of some coral reef ecologists or NGOs looking to use satellite remote sensing to monitor coral reef ecosystems.

Launched in 2010, Google Earth Engine (GEE) is a cloud-based geoprocessing platform, which enables access to a wide variety of satellite remote sensing data sets for analysis either within GEE or to download and analyse externally with other software [51]. Here, we use GEE to obtain environmental variables known to impact stress on coral reef ecosystems and map coral exposure to these environmental stressors, building on the approach of Maina et al. [50]. Our aims were to 1) assess the ability of GEE to access and integrate multiple different environmental variables known to have an impact of coral reef stress; 2) develop a user friendly, free and open, spatially and temporally-explicit, coral reef stress exposure index using GEE, which can be used to assign stress scores for use in research, conservation and management at a global scale; and 3) investigate the utility of this index in three well documented regions known to have been impacted by high stress events over the past twenty years, that represent a range of environmental conditions and where information on bleaching events were available; the Chagos Archipelago; the central Saudi Arabian Red Sea; and the Gilbert Islands of the Republic of Kiribati.

\section{Materials and Methods}

This section describes the development of the Coral Reef Stress Exposure Index (CRSEI), which was written in the GEE JavaScript API (https://github.com/mjw-marine/Coral-Reef-Stress-Exposure-Index).

\subsection{Variable selection and threshold definition}

To inform variable selection for the CRSEI, a review of the literature was undertaken using the terms 'coral', 'health', 'stress', and 'environment' in Google Scholar (https://scholar.google.co.uk/). Variables were chosen if they 1) had previously shown to have an effect, positive or negative, on coral reef stress, 2) had defined ecological health-based thresholds, that allow for discrimination between healthy and unhealthy reefs, and 3) were available as products in GEE. Thresholds are defined 
as limiting values of an environmental variable, which, if exceeded, can cause stress and health deterioration for coral reef ecosystems. Specific thresholds were extracted during the literature review to parametrise the inputs for the CRSEI. The variables selected and thresholds identified, including references, can be found in Table 1. Wherever possible, globally applicable thresholds were identified from the literature, but where these could not be found, thresholds based on regional studies were used and assumed to be applicable at a global scale.

\subsection{Remote sensing data}

This study used satellite remote sensing data available within GEE. Products from a priori selected variables (Table 2) were chosen because they were available in GEE, at appropriate spatial and temporal resolutions and had global coverage (Table 2). If two or more products were available for the same variable, the product with the greatest spatial resolution was chosen.

Only one bathymetry product, ETOPO1, was available in GEE, which, with a spatial resolution of 1 arc-minute, was deemed too coarse for this study. Instead we utilised the method developed by Li et al. [52] for automatic global shallow water depth mapping, which utilises Sentinel-2 reflectance data to obtain shallow water bathymetry at a resolution of $10 \mathrm{~m}$ in GEE. We used Sentinel- 2 data from $1^{\text {st }}$ January 2019 to $31^{\text {st }}$ December 2020 to generate a fixed depth map, as in Li et al. [52], since depth changes over very long time scales. To speed up processing in GEE this data was downloaded as a product to be called on in GEE and has been included as public asset in GEE (https://code.earthen-

gine.google.com/?asset=users/mjw1280/Automated Shallow Water Bathymetry Mapping) and included in github for free and open use (https://github.com/mjw-marine/Coral-Reef-Stress-Exposure-Index).

Data values for SST and wind were obtained directly from the GEE product and used to calculate the CRSEI. However, some variables required pre-processing prior to analysis. Ocean current data obtained from HYCOM Sea Water Velocity in GEE are available in both eastward and northward directions and at multiple depths. To avoid wind driven surface processes, current values at $10 \mathrm{~m}$ depth were chosen for this study. Overall current speed was calculated using the formula: overall current $=\sqrt{ }$ northward ${ }^{2}+$ eastward $^{2}$. For this study, information on direction was discarded and only current speed was used. 
Table 1. Variables used for the assessment of coral reef stress. Variables were grouped by stressors (primary drivers of coral reef stress) and reducers (those that mitigate the primary effects of stressors) informed by data from Maina et al. [50]. Upper and lower thresholds obtained from the literature are provided with variable units and threshold references. Variables were given values of 0 and 1 for lower and upper thresholds respectively. Reliability factor was informed from data from West and Salm [32], and is an indicator of how reliably this variable impacts coral stress at a global scale. Scale indicates whether the threshold is seen at a regional or global scale.

\begin{tabular}{l|l|l|l|l|l|l|l}
\hline Stress variable & Unit & Stress category & Lower threshold & Upper threshold & Reliability factor & Scale & Reference \\
\hline cloud cover & oktas & Reducer & 3.0 & 7.0 & low & Regional & {$[30]$} \\
\hline current & $\mathrm{m} / \mathrm{s}^{1}$ & Reducer & 0.13 & 0.15 & high & Regional \\
\hline depth & $\mathrm{m}^{1}$ & Stressor & $<10$ & $>20$ & high & Regional \\
\hline DHW & weeks & Stressor & 4.0 & 8.0 & high & Regional & {$[29,54]$} \\
\hline salinity & $\mathrm{ppt}$ & Stressor & $32.0-38.0$ & $<26.0$ or $>45.0$ & low & Regional & {$[55]$} \\
\hline SST & ${ }^{\circ} \mathrm{C}$ & Stressor & $21.0-27.0$ & $>30.0$ or $<18.0$ & high & Global \\
\hline SST anomaly & ${ }^{\circ} \mathrm{C}$ & Stressor & 1.0 & 2.0 & high & Global & {$[27,50]$} \\
\hline SST variability & ${ }^{\circ} \mathrm{C}$ & Reducer & 4.0 & 10.0 & high & Regional & {$[49]$} \\
\hline wind & $\mathrm{m} / \mathrm{s}^{1}$ & Stressor & $8.0-28.0$ & $<5.0$ or $>33.0$ & low & Regional & {$[53]$} \\
\hline
\end{tabular}


Table 2. Variables used for the assessment of coral reef stress, including source and temporal and spatial resolution. All information on variable products can be found in the Earth Engine Data Catalogue (https://developers.google.com/earth-engine/datasets/).

\begin{tabular}{|c|c|c|c|c|c|}
\hline Variable(s) & $\begin{array}{l}\text { Temporal } \\
\text { resolution } \\
\text { (hour) }\end{array}$ & $\begin{array}{l}\text { Spatial } \\
\text { resolution } \\
(\mathbf{k m})\end{array}$ & Start year & End year & $\begin{array}{l}\text { Data source (https://developers.google.com/earth- } \\
\text { engine/datasets/catalog/) }\end{array}$ \\
\hline cloud cover & 3 & 11 & 1978 & present & $\begin{array}{l}\text { NOAA Climate Data Record (CDR) of Cloud Properties } \\
\text { from AVHRR Pathfinder Atmospheres - Extended } \\
\text { (PATMOS-x), Version } 5.35 .3[57]\end{array}$ \\
\hline current, salinity & 24 & 9 & 1992 & present & $\begin{array}{l}\text { HYCOM: Hybrid Coordinate Ocean Model, Water Velocity } \\
\text { [58] }\end{array}$ \\
\hline depth & NA & 0.1 & 2017 & present & Sentinel-2 MSI: MultiSpectral Instrument, Level-2A [52] \\
\hline DHW & 24 & 0.5 & 2002 & present & $\begin{array}{l}\text { Ocean Color SMI: Standard Mapped Image MODIS Aqua } \\
\text { Data [59] }\end{array}$ \\
\hline $\begin{array}{l}\text { SST, DHW, SST anomaly, SST } \\
\text { variability }\end{array}$ & 24 & 0.5 & 2002 & present & $\begin{array}{l}\text { Ocean Color SMI: Standard Mapped Image MODIS Aqua } \\
\text { Data [59] }\end{array}$ \\
\hline wind & 24 & 27 & 1988 & present & $\begin{array}{l}\text { NOAA Ocean Surface Bundle (OSB) Climate Data Record } \\
\text { (CDR) of Near-surface Atmospheric Properties, Version } 2 \\
{[60]}\end{array}$ \\
\hline
\end{tabular}


MODIS Aqua SST data was used to obtain SST anomaly, SST degree heating weeks (DHW), and SST variability. For SST anomaly, the monthly mean of ten years (20022012) of SST values for the region was calculated and subtracted from the SST value for each pixel for the corresponding month in the collection to obtain SST anomaly, following the method by Eakin et al., [49] (e.g., if the SST value of a pixel was from January, the mean SST value from January was subtracted from that pixel). DHW was calculated following the method of Eakin et al. [49]. The SST anomaly was averaged for each 7-day time frame to create a weekly mean for 12,7 -day periods prior to the final date of the period of interest. The number of weeks where the weekly mean was $1^{\circ} \mathrm{C}$ above the tenyear mean was counted to give DHW for each region of interest. For SST variability, the minimum SST value was subtracted from the maximum SST value for each pixel from the collection for each reef region in the time series.

\subsection{Data accuracy and uncertainty}

The reliability of this index depends on the accuracy of the input datasets [61]. Where available, the accuracy metric of the variables used for the CRSEI can be found in Supplementary Table S1. Satellite remote sensing data and ocean model data are now regularly available at resolutions of less than $10 \mathrm{~km}$ [62]. Due to the relative sparseness of global in situ data, the ocean dynamics of some variables are not adequately observed at these fine scales, and, as such, error estimates for marine variables are not always available at a global scale, which is a common challenge for operational oceanography [62]. In these cases, regional accuracy values, from site specific studies, have been included.

\subsection{Variable categorisation and selection}

Following the method proposed by Maina et al. [50], variables were assigned into two categories; stressors and reducers, using data from West and Salm [32] and Maina et al. [50] (Table 1). Stressors were considered the primary negative drivers of coral reef stress. Reducers can play an important role in coral reef resilience $[63,64]$. Reducers mitigate the primary effects of stressors, and as such, have a positive impact on coral reef ecosystems. All a priori selected variables were included in the score and variables were weighted according to reliability (Table 1), where reliability was defined as whether a variable is considered predictable and persistent in their impacts on coral reef stress, taken from West and Salm [32]. Although not featured in West and Salm [32], salinity was also deemed low reliability, due to the variability in impact and salinity tolerance in many species [65-67]. Those variables that had low reliability were weighted $50 \%$ less than high reliability factors.

\subsection{Coral Reef Stress Exposure Index}

Stress exposure scores (SE) were calculated for each variable (with weightings), and the mean of these calculated to form the CRSEI. A time period of one month was selected to aggregate the SE score for each variable, except for DHW where 12 weeks were used to match the calculation period from NOAA coral reef watch [49]. The threshold values obtained from the literature were used to assign a value to each variable between 0 and 1 using discontinuous functions (fuzzy logic). For both stressor and reducer variables, values below the lower threshold are assigned a score of 0 and values above the upper threshold are assigned a score of 1 (Figure 1, Table 1). Values between the thresholds were assigned a score defined by a linear function of the form $y=m x+c$, where $m$ is the gradient and $\mathrm{c}$ is the intercept. For example, given a variable with the lower threshold ( 0$)$ of 30 and upper threshold (1) of 40, the linear function $y=1 / 10 x-3$, where $m=(1-$ $0) /(40-30)$ and $c=-1 / 10 \times 30$, would be applied to all values between the two thresholds (Figure 1). 


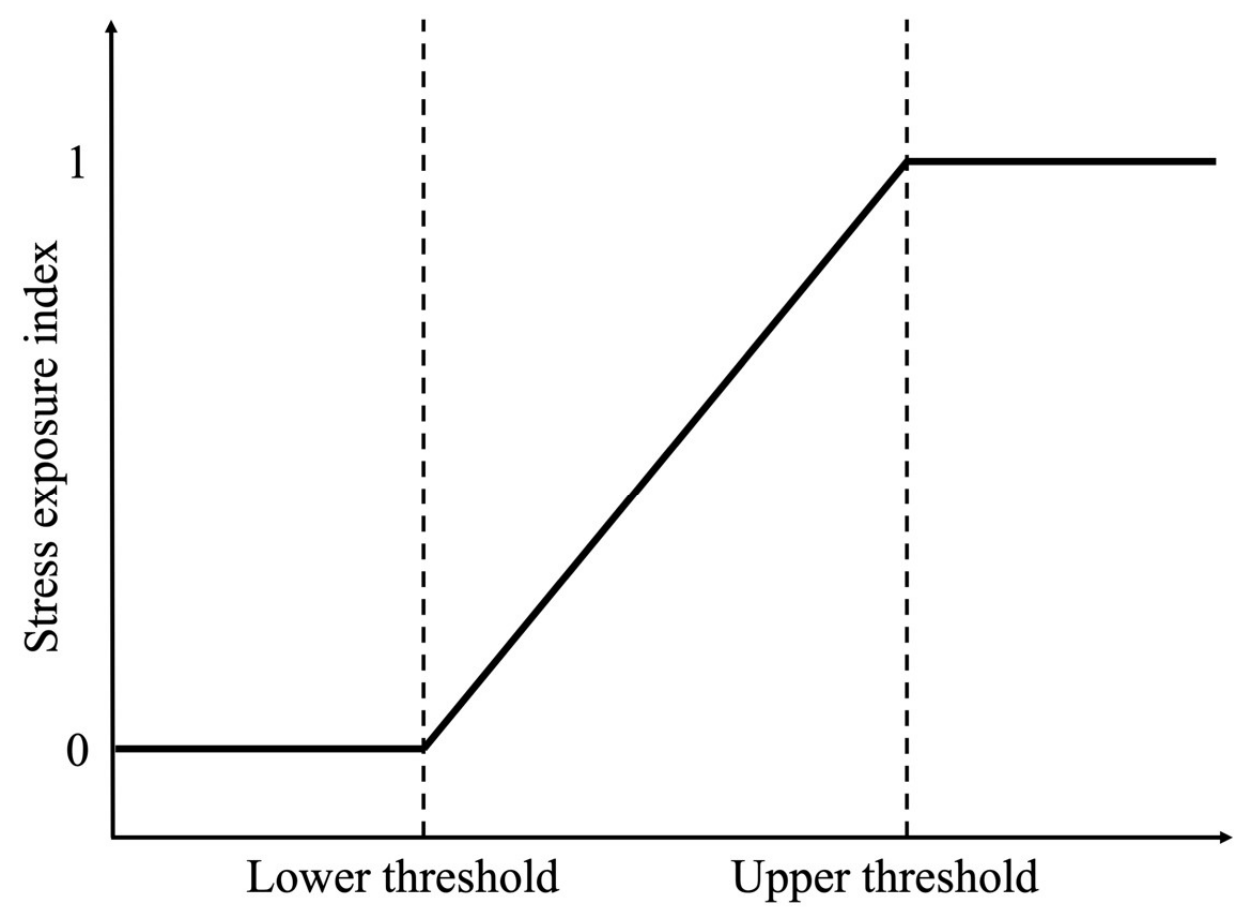

Variable value

Figure 1. Discontinuous functions, including thresholds for 0 and 1 values, for defining stress exposure scores for each variable stressor and reducer variable.

Following the weighting of each variable, a SE score for each variable was calculated and exported from GEE. The CRSEI was calculated in R [68] using the following formula:

$$
\text { CRSEI }=\frac{\Sigma(\text { Stressor }-\Sigma(\text { Reducer })}{N(\text { Variables })}
$$

where $\Sigma$ (Stressor) is the sum of the SE score of the stressor variables, $\Sigma$ (Reducer) is the sum of the reducer variables and $\mathrm{N}$ (Variables) is the total number of variables. The $\mathrm{R}$ code for calculating the CRSEI from GEE data can be found at https://github.com/mjwmarine/Coral-Reef-Stress-Exposure-Index. Remote sensing data can be unavailable during certain periods (e.g., long periods of cloud cover). Whenever data for a specific variable was missing for a specific period and site, this variable was omitted from the CRSEI score. If two or more variables were missing for the entire study period at a site, this site was removed from the analysis.

The CRSEI is scored between 0 and 1 , with 0 being no stress, and 1 equating to the maximum amount of stress. Instances where negative CRSEI scores occurred from low stress values but high reducer values indicate low stress and are therefore converted to 0 . A methodological process flow of the final score can be found in Figure 2. 


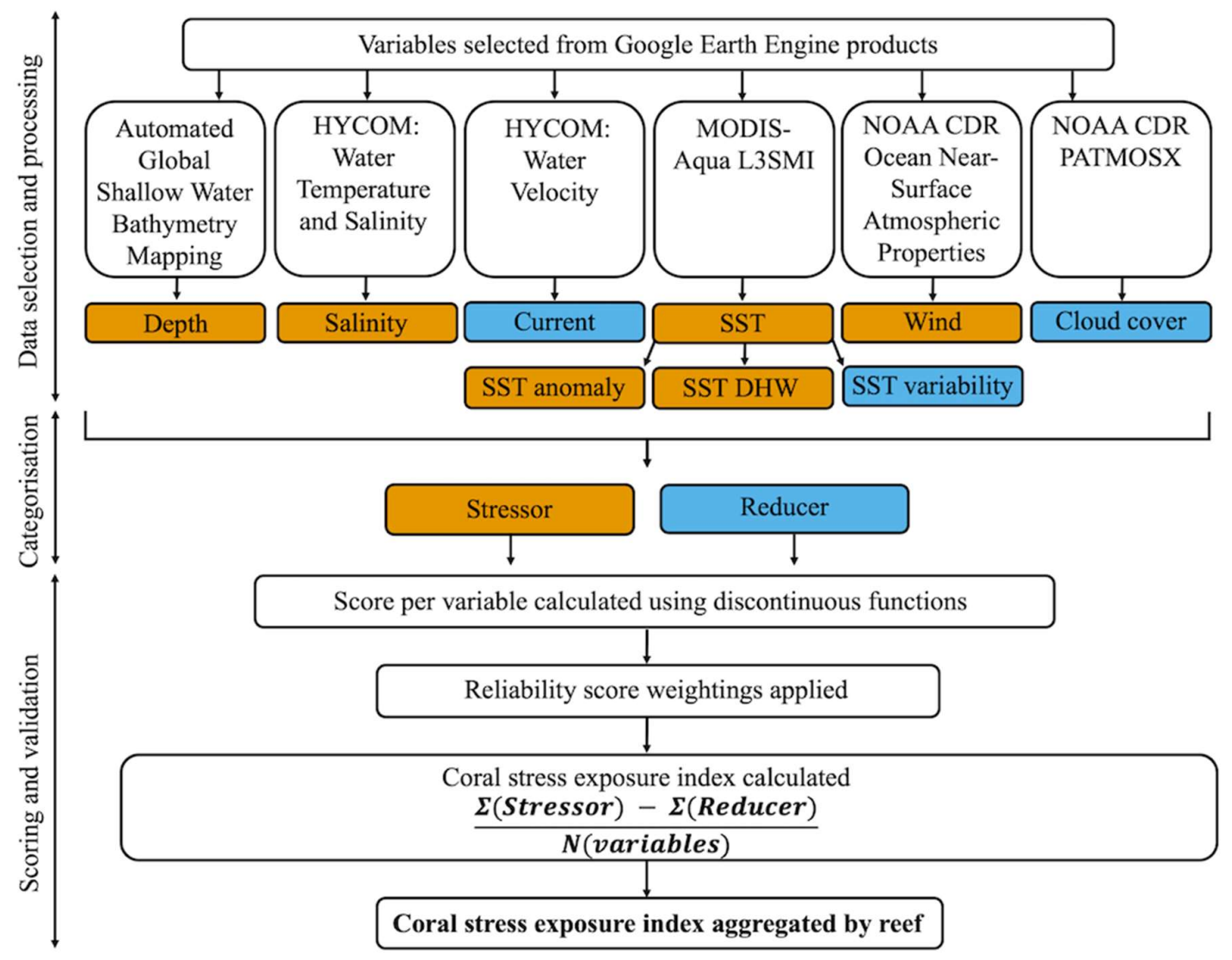

Figure 2. Methodological process flow for developing the coral stress exposure index (CRSEI). Stressors are highlighted in orange, reinforcers green and reducers blue.

\subsection{CRSEI for global reefs}

To assess the utility of the CRSEI at a global scale, CRSEI scores were calculated for 12 coral reef ecosystem regions as outlined in Maina et al., [50]. We define a reef as a single connected reef, a site as a collection of different localised reefs and a region as a collection of sites within the same area. To calculate a CRSEI at each reef, a buffer of $500 \mathrm{~m}$ was created around the latitude and longitude position of each reef, to match the resolution of many of the products selected, and to avoid overlap of the nearby reefs where data was also to be extracted. A SE score (with weightings) was calculated for each variable, and a CRSEI was calculated from the mean of these variable SE scores for each site. CRSEIs were calculated for each of the 3157 reefs from the 12 coral reef ecosystem regions and mean CRSEI scores and summary statistics for each ecosystem region were calculated. All analyses were conducted using R version 4.0.3 [68].

El Niño periods have been shown to cause stress to coral reef ecosystems [69,70]. To assess if the CRSEI can detect differences in stress levels within reef ecosystems, CRSEI values were calculated for a potential period of low stress, a non-El Niño period (April 2012), and potential period of high stress, a strong El Niño period (April 2016). Linear mixed effects models were used to assess if CRSEI scores differed between non-El Niño and El Niño periods, with CRSEI score included as a response variable, El Niño/non-El Niño as a categorical explanatory variable and 'coral reef ecosystem region' as a random effect, using the 'lmer' function in the lme4 package [71]. This analysis was not conducted to be used as an indicator for El Niño per se, as an El Nino index is 
already well established. More it was used to indicate that the CRSEI can identify intra-, and inter-, regional differences in stress at a global scale.

\subsection{Case Study}

Due to the often remote locations of coral reef ecosystems, and high costs of surveys, regular widespread in situ data on coral reef stress is not readily available. To assess the ability of CRSEI to assist in obtaining long time-series of stress on coral reefs, three study regions were chosen; the Chagos Archipelago; the central Saudi Arabian Red Sea; and the Gilbert Islands of the Republic of Kiribati (Figure 3). These three regions represent a range of ocean and environmental conditions, they have experienced significant bleaching events over the past 20 years and have all been extensively monitored and well documented in the literature [see Sheppard et al., [72], Head et al., [24], Carilli et al., [73], Donner \& Carilli [74], Furby et al., [75] and Monroe et al., [76]].

Following the El Niño events of 2015/16, coral reefs in the Chagos Archipelago experienced extensive bleaching and declines in coral cover in the region [24,72]. Coral reefs of the Gilbert Islands of the Republic of Kiribati and the central Saudi Arabian Red Sea also experienced El Niño linked bleaching and declines in 2004 and 2010 [73,74], and 2010 and 2015 [75,76], respectively. Overall mean monthly CRSEI scores, which include SE scores for each variable, were calculated quarterly (January, April, July, October) from 2003-2016 from 34 different sites across the three regions (BIOT =12, Gilbert Islands $=11$, central Red Sea $=11)$ (Supplementary Table S2) using the global threshold scores obtained from the literature. This period covers six different El Niño events (2002/2003, 2004/2005, 2006/2007, 2009/2010, 2014/2015, 2015/2016) some of which coincided with bleaching events in these regions. 


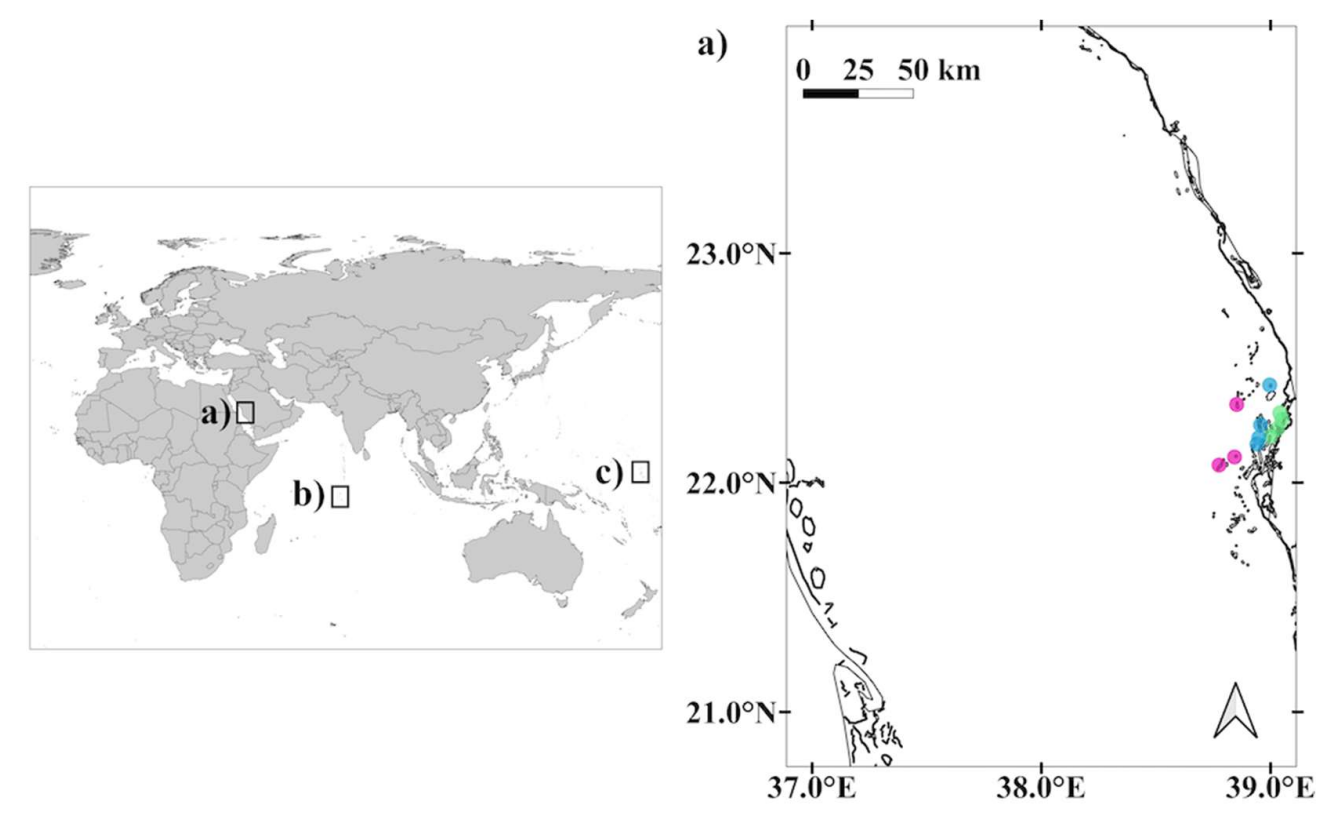

central Red Sea sample sites

- Inshore Reef $\bullet$ Midshelf Reef $\bullet$ Offshore Reef
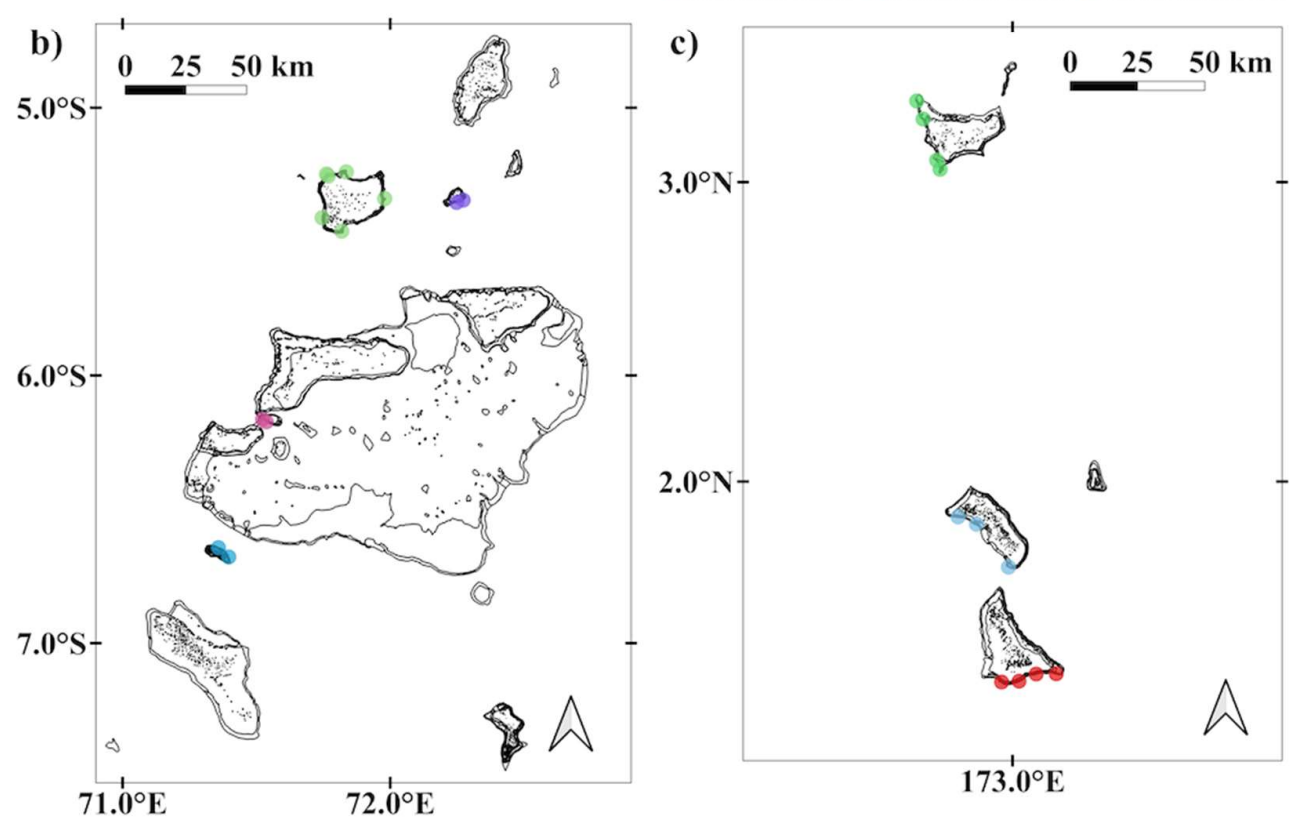

Chagos Archipelago sample sites

- Egmont • Grand Chagos Bank • Saloman - Peros Banhos

Gilbert Islands sample sites

- Abaiang Butaritari • South Tarawa

Figure 3. Three study regions; a) the central Saudi Arabian Red Sea; b) the Chagos Archipelago; iii) the Gilbert Islands of the Republic of Kiribati used for sampling, with sites identified. Scale, north arrow and coordinates are provided. 
A CRSEI for each site, and SE for each variable per site, was calculated from the CRSEI scores from each reef at each site using the method mentioned above. Using these SE scores, Principal Component Analysis (PCA) was used to detect spatial differences between the different regions based on the 9 identified stress variables using the 'prcomp' function in the stats package in R [68]. Box plots were plotted to investigate spatial (regional) and temporal (non-El Niño events, El Niño events, and El Niño events coinciding with bleaching events) differences between stress variables within regions. Linear regression was used to identify any temporal trends in CRSEI using the ' $1 \mathrm{~m}^{\prime}$ function in the stats package [68].

\subsection{Global vs site specific thresholds}

The values at which environmental variables may cause stress to coral reef ecosystems can be very region specific [30,77-79]. For example, upwelling events have been shown to provide protection to reefs from bleaching but only in specific regions and time periods [80], and in some areas may even exacerbate bleaching in certain regions [81]. As such region-specific thresholds could be very important for the accuracy and utility of the CRSEI.

To test if there were differences in CRSEI when using global or location-specific thresholds, region-specific thresholds for the Chagos Archipelago, where available, were obtained from the literature (Supplementary Table S3), and CRSEI scores visually and statistically compared. CRSEI scores were tested for normality using the 'shapiro_test' function in the stats package. As data were non-normal Wilcoxon signed rank tests were used rather than t-tests [82] using the 'wilcox.test' function in the in the stats package [68].

\subsection{Google Earth Engine App}

GEE provides a platform for users to publish their own apps (https://www.earthengine.app/), which allows for dynamic interfaces for users, and increases accessibility to GEE products for non-expert users [83]. As such, in order to increase the potential and use of the CRSEI, a CRSEI app was developed as part of this study.

\section{Results}

Final code for the CRSEI, written in GEE JavaScript API, can be found as GitHub repository (https://github.com/mjw-marine/Coral-Reef-Stress-Exposure-Index). In addition, a CRSEI GEE app can be found at https://mjw1280.users.earthengine.app/view/coral-reef-stress-exposure-index.

\subsection{Global scale variability in coral stress exposure}

Figure 4 shows the spatial distribution of the CRSEI across the 12 coral reef ecosystem regions during El Niño and non-El Niño periods, illustrating the utility of the index and the GEE tool for investigating spatial and temporal variability in coral reef exposure to environmental stressors. Linear mixed effects models indicated that there was a significant difference in CRSEI between an El Niño period (April 2016) and a non-El Niño period (April 2012), with non-El Niño periods having significantly lower CRSEI scores compared to El Niño periods (estimate $=-0.043 \mathrm{p}<0.001$, Figure 5). However, as Figure 5 shows, there is considerable regional variation in the impacts of El Niño periods on coral stress. Summary statistics of CRSEI scores between the 12 regions can be found in Supplementary Table S4. 

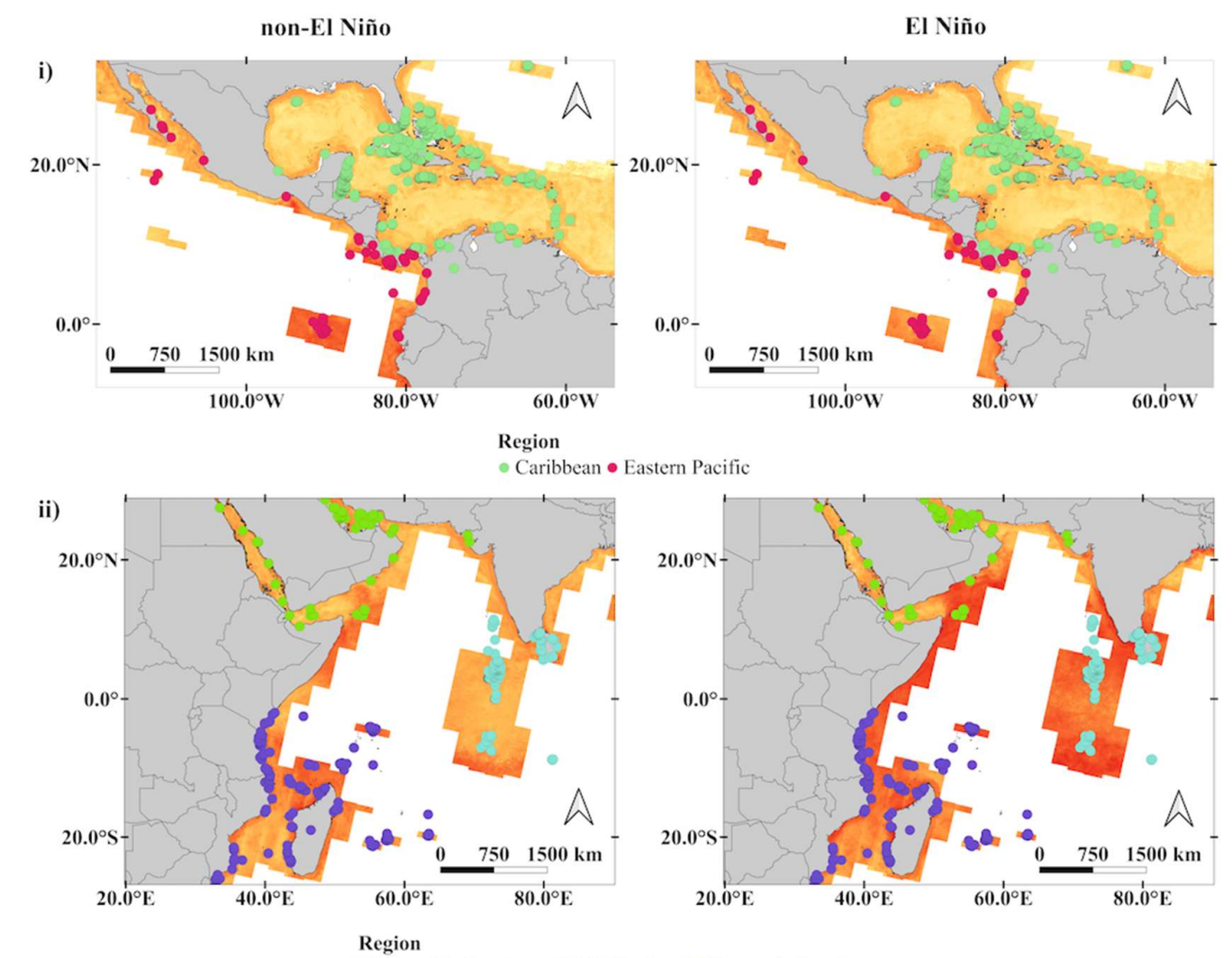

- Central Indian Ocean • Middle East • Western Indian Ocean

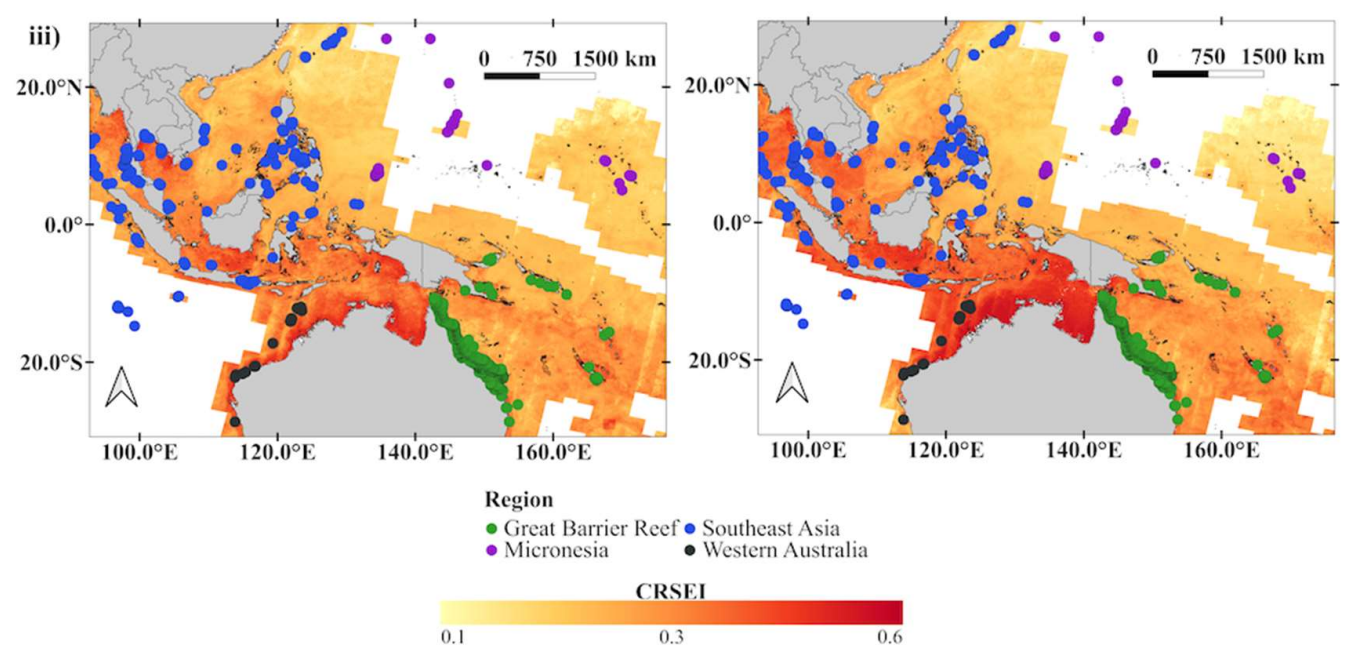

Figure 4. Global CRSEI maps from a non-El Niño period (April 2012) and a strong El Niño period (April 2016) for i) the Caribbean and Eastern Pacific, ii) Indian Ocean and Middle East and iii) Southeast Asia, Indonesia and Australasia. The distribution of reefs sampled is indicated with coloured circles. Scale, north arrow and coordinates are provided. Colour scale for the CSREI is also provided Note that Sentinel 2, used in this study for obtaining shallow water bathymetry data, does not collect data over open oceans. As such, the white spaces seen here are due to the lack of Sentinel-2 data to calculate CRSEI in these areas. 


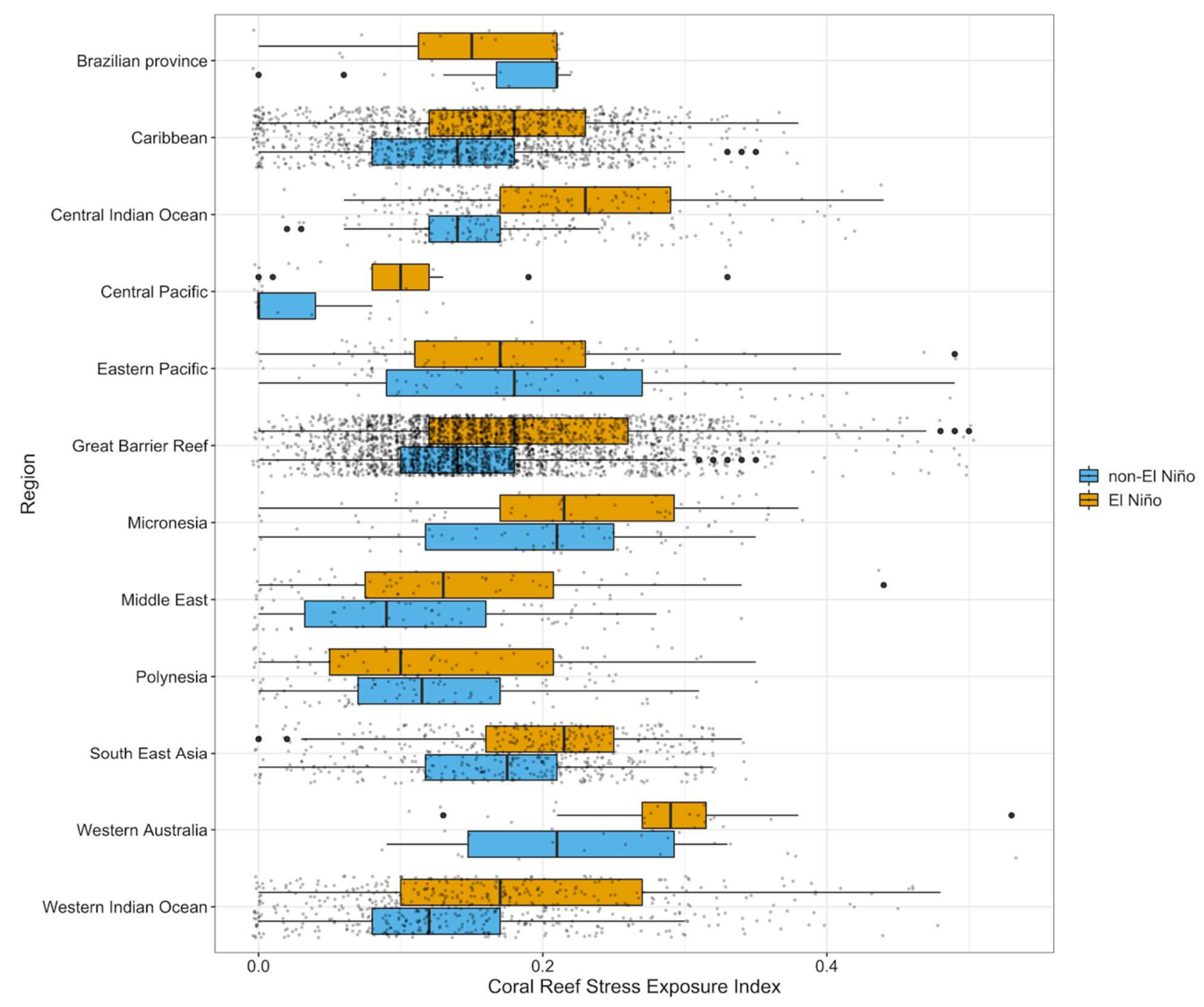

Figure 5. Box plots of the distribution of CRSEI scores between non-El Niño periods (April 2012), and strong El Niño periods (April 2016) by different coral reef ecosystem region. Box plot represents median CRSEI and the interquartile range. Whiskers extend from the hinge to the highest and lowest values within $1.5 \mathrm{x}$ the interquartile range. Any values outside that are indicated as outliers.

\subsection{Case studies}

Across the three case study regions, data were collected on all 9 variables for 33 of the 34 reefs. One site from the Gilbert Islands (TRW008) was not included in the final analysis as there was no data available on wind, current, and depth at this site throughout the study period. Data were not always present for every variable for every quarterly time period in each region. Wind data were not included in the PCA as data availability was highly variable across the Gilbert Islands and central Red Sea regions but wind data, where available, did still contribute to the overall CRSEI score. A further five sites across the three regions were removed from the PCA analysis as they were not able to obtain data on a single variable throughout the study period (Supplementary Table S2). However, they still did contribute to the overall CRSEI score.

\subsection{Inter-region variance}


The CRSEI was used to investigate long-term trends for each case study region over a 14-year period (2003-2016) (Figure 6). The Chagos Archipelago showed fluctuations in CRSEI around a stable value. The CRSEI was able to identify peaks in stress coinciding bleaching events in El Niño years for the Chagos Archipelago. There were also peaks for the Gilbert Islands during bleaching event years, but also peaks in El Niño years that did not coincide with bleaching events. CRSEI for the central Saudi Arabian Red Sea showed a regular periodic cycle, with no clear peaks in El Niño years. Results from linear models indicate that there was significant change over time in CRSEI, with stress increasing gradually in the central Red Sea (estimate $=0.006, \mathrm{~F}_{1}=16.90, \mathrm{p}<0.001$ ), Chagos Archipelago (estimate $=0.009, \mathrm{~F}_{1}=46.13, \mathrm{p}<0.001$ ) and Gilbert Islands (estimate $=0.008, \mathrm{~F}_{1}=$ 15.24, $\mathrm{p}=0.001$, Figure 6).

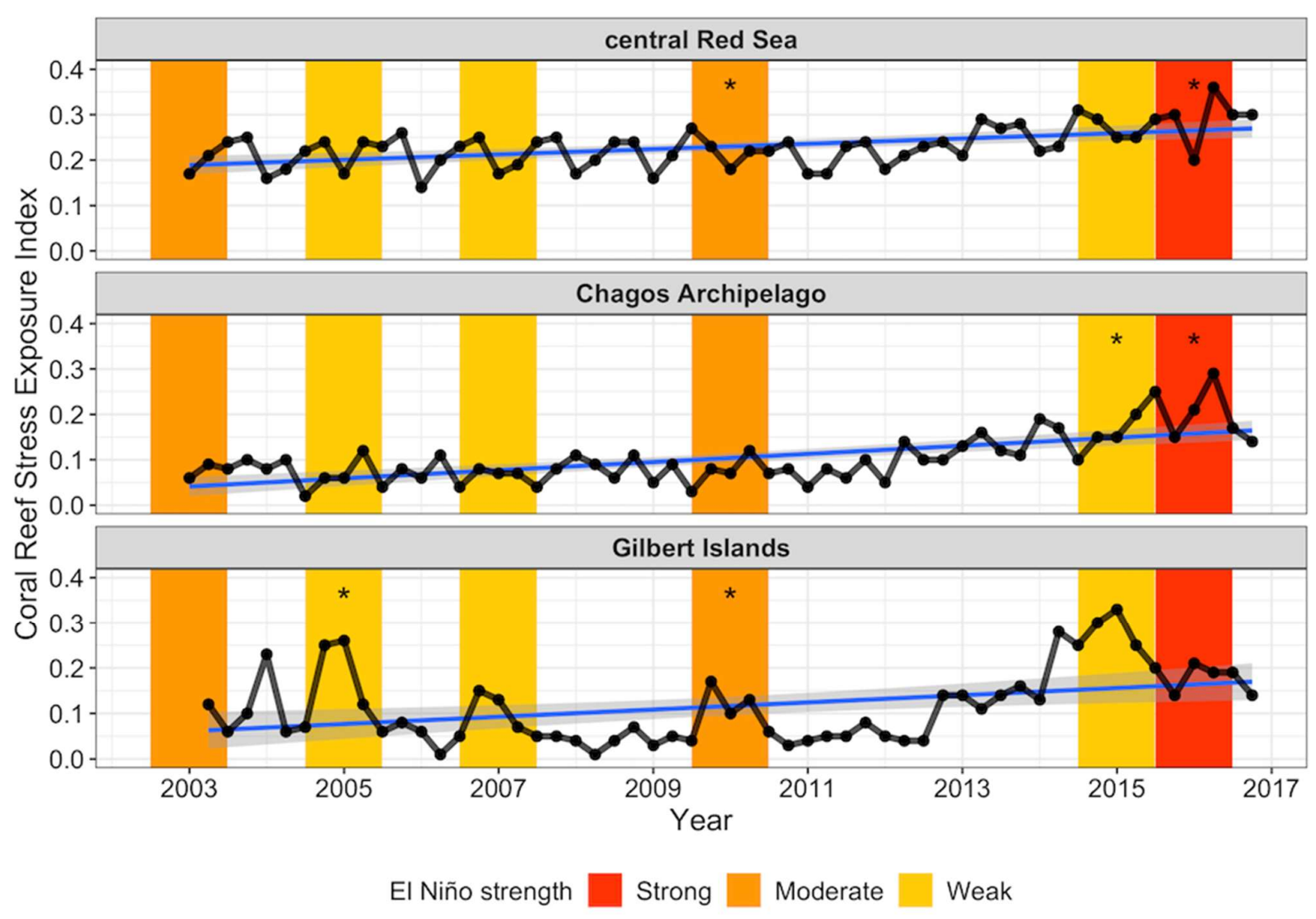

Figure 6. Mean monthly CRSEI scores taken quarterly from all sites (January, April, July and October) from the central Saudi Arabian Red Sea, the Chagos Archipelago and the Gilbert Islands in the Republic of Kiribati; and from 01/01/2003 - 31/12/2016. Trend line in blue with $95 \%$ standard error in grey. El Niño events are highlighted by strength; strong $=$ red; moderate $=$ orange; and yellow $=$ weak. Asterisks note El Niño years where bleaching events occurred during this period.

The CRSEI was also able to indicate differences in the impact of individual variables between the three regions. Figure 7 shows the score of each site for the first two principal components with SE and the loading of each environmental variable on the first two principal components. Scree plots indicate that the first two principal components (PC) capture most of the variation of the data (Supplementary Figure S1). Total percentage variance accounted for by the first 2 PCs was $81.1 \%$. Depth and current 
accounted for the greatest contribution of the variance to the first PC. SST variability and SST anomaly were the most important contributors to the second PC. Current and cloud were all highly correlated in the first PC, and SST, SST anomaly and DHW highly correlated in the second PC. Depth was the most uncorrelated with the other variables. Sites within the same region had variable SE scores most similar to each other, but there were outliers within the regions (e.g., OS1 and TRW010), indicating that there is also variance in how variables may contribute to the CRSEI within a region. The central Red Sea had considerably different variable SE scores to the Chagos Archipelago and the Gilbert Islands which were more similar to one another, perhaps due to the remoteness of their locations.

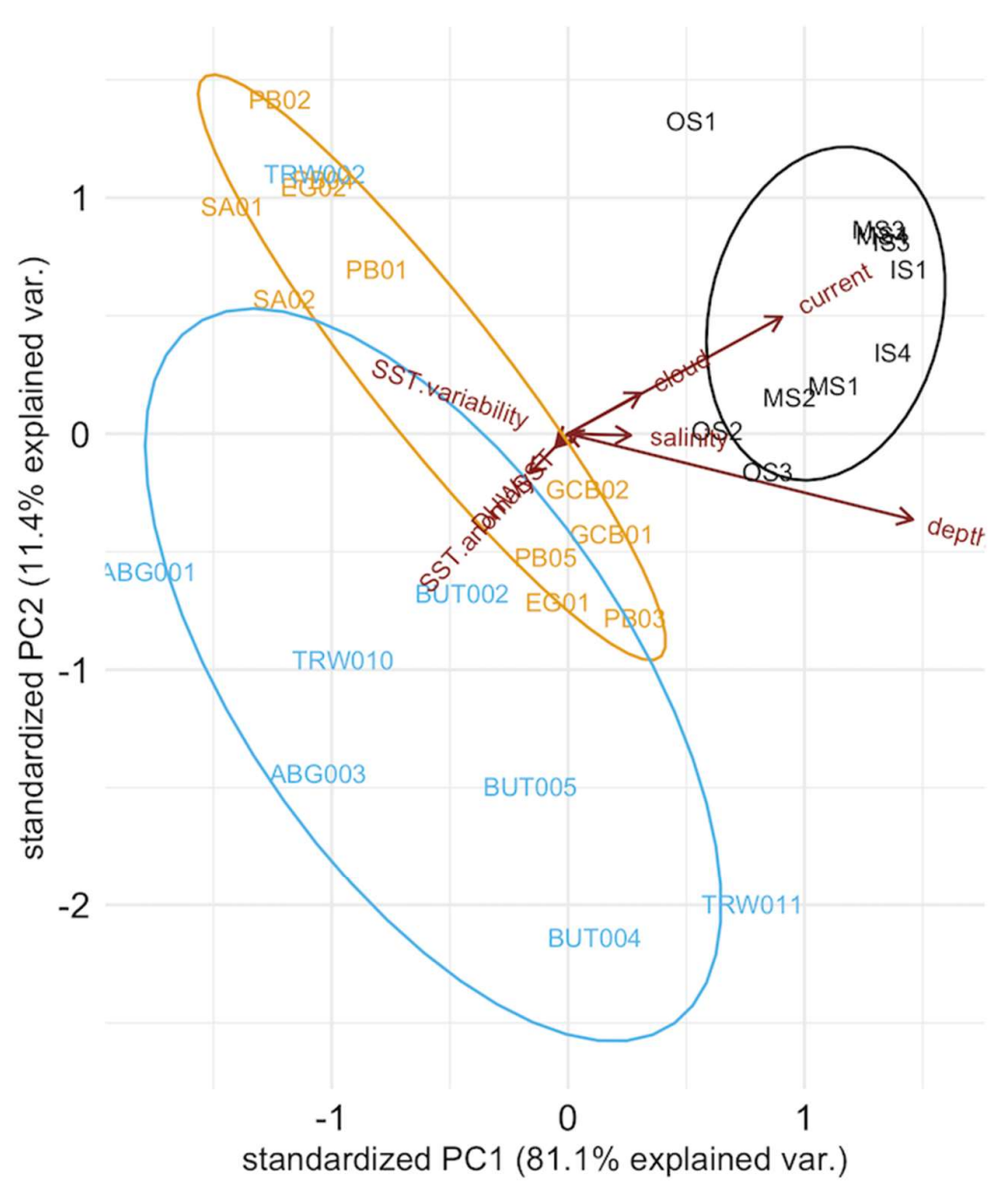

Site $\rightarrow$ central Red Sea $-a$ Chagos Archipelago - Gilbert Islands

Figure 7. Biplots of the different samples of reefs and regions from PCA of SE scores for environmental variables used in the CRSEI. $X$ and $Y$ axes show normalized principal component scores.

\subsection{Intra-region variance}

Temporal intra-region variance in variable SE scores was seen between sites in the Chagos Archipelago and the Gilbert Islands, with differences in scores between non-El 
Niño years and El Niño years with and without a bleaching event (Figure 8). In the Chagos Archipelago, El Niño years in which a bleaching event took place had much higher DHW and SST anomaly scores compared to non-El Niño and El Niño years, with no obvious differences in the other variable SE scores. In the Gilbert Islands Non-El Niño years had a lower variable SE score for SST, DHW, and SST anomaly, and greater variable SE for current, with no obvious difference in stress variable distribution between El Niño years and El Niño years with a bleaching event. In the central Saudi Arabian Red Sea there was a slight increase in the SE score for SST anomaly and SST between El Niño years with a bleaching event and El Niño and non- El Niño years, but no obvious differences in the other variables.

Figure 9 shows intra-region variation in CRSEI, between non-El Niño and strong El Niño years. Intra-region spatial differences in stress have been reported in the Gilbert Islands $[73,74]$ and the central Red Sea $[75,76]$, and the CRSEI provided further evidence in support of this. Distributions of variable SE scores showed differences between sites in both the Gilbert Islands and the central Red Sea (Figure 10). DHW contributed very little to the CRSEI at Butaritari in the Gilbert Islands compared to Abaiang and South Tarawa. South Tarawa had greater contributions from depth, salinity and current to the CRSEI than Abaiang and Butaritari. In the central Red Sea, depth and current played a greater contribution to the CRSEI in Offshore than Midshelf and Inshore sites.

\subsection{Global versus region specific thresholds}

Shapiro tests indicated that CRSEI scores for both global and Chagos Archipelago regional thresholds were non-normal ( $p<0.001$ and $p<0.001$ respectively). The Wilcoxon signed rank tests indicated that there was no significant difference between the global threshold and Chagos Archipelago regional threshold CRSEI scores (Supplementary Figure S2). 

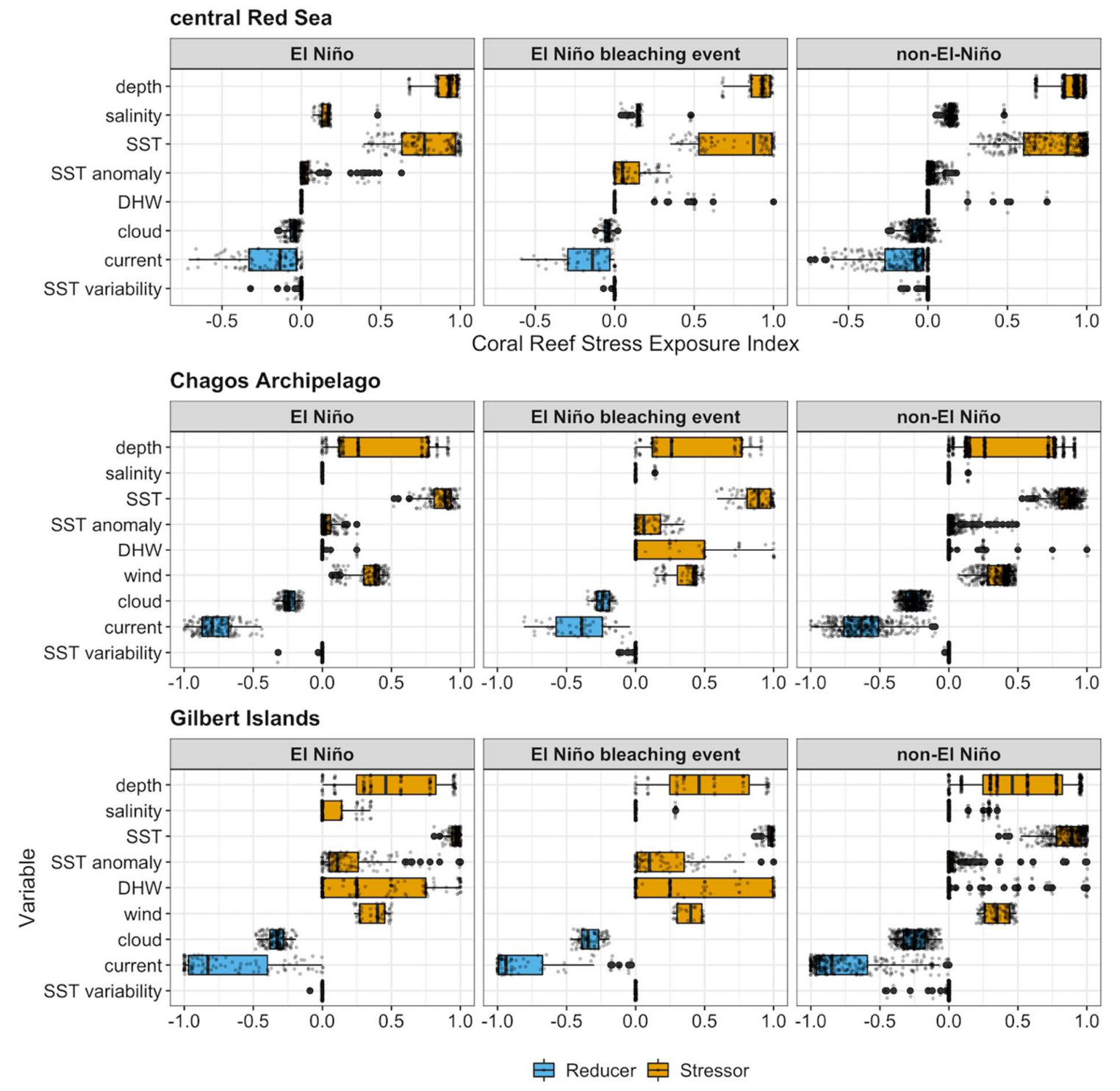

Figure 8. Box plots of the distribution of variable SEI scores between El Niño years, El Niño years with bleaching events and non-El Niño years by different region. Reducers are represented as negatives in the figure to show that they reduce the stress on coral reefs. Note that cloud, salinity and wind are weighted at $50 \%$ of the other stressors and as such, can only have a max SE score of 0.5 (or -0.5 for cloud which is a reducer). 

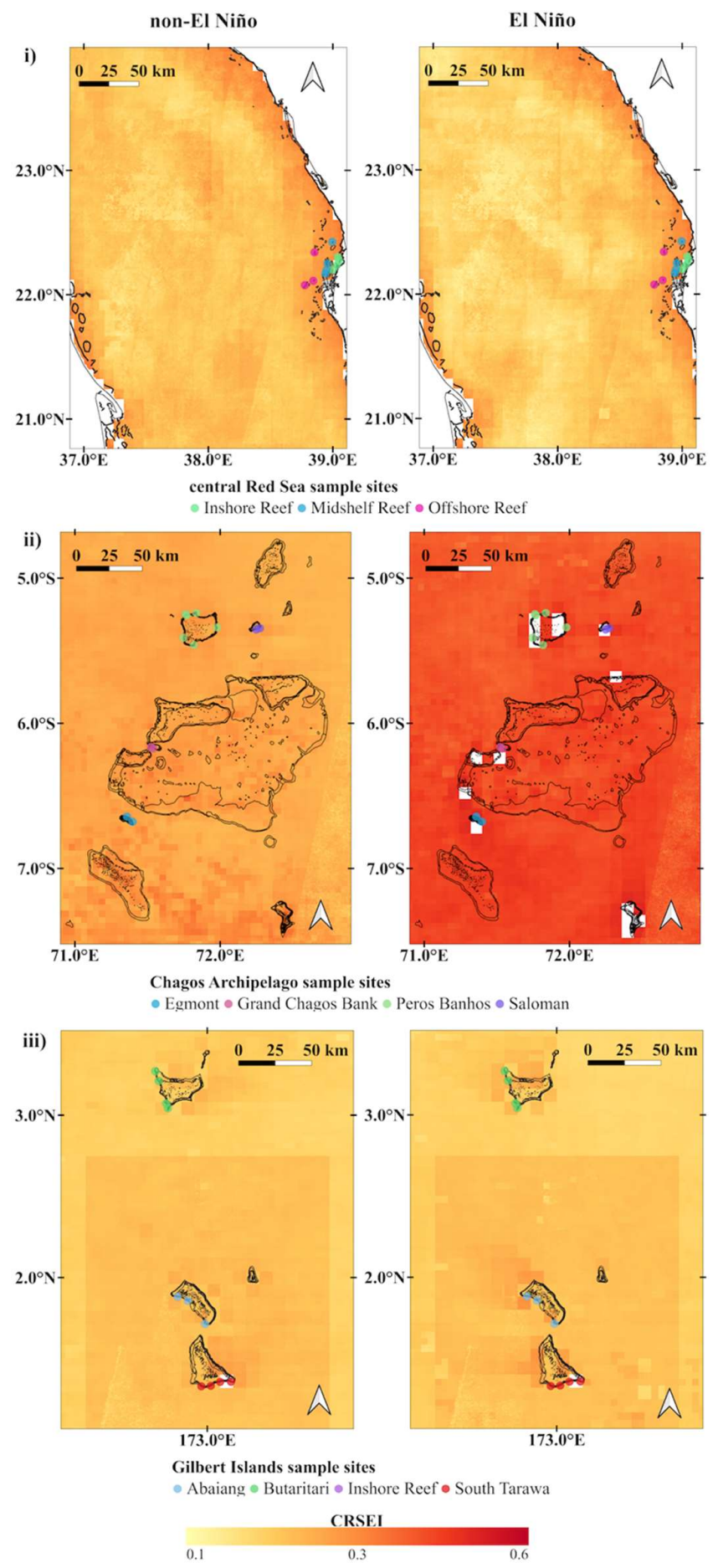

Figure 9. Monthly CRSEI across the Chagos Archipelago between a non- El Niño period (April 2012) and a strong El Niño period (April 2016) in i) central Red Sea, ii) Chagos Archipelago, and iii) Gilbert Islands. Scale, north arrow, and coordinates are provided. Colour scale for the CSREI is also provided. Blank pixels indicate no score was calculated for that pixel. 

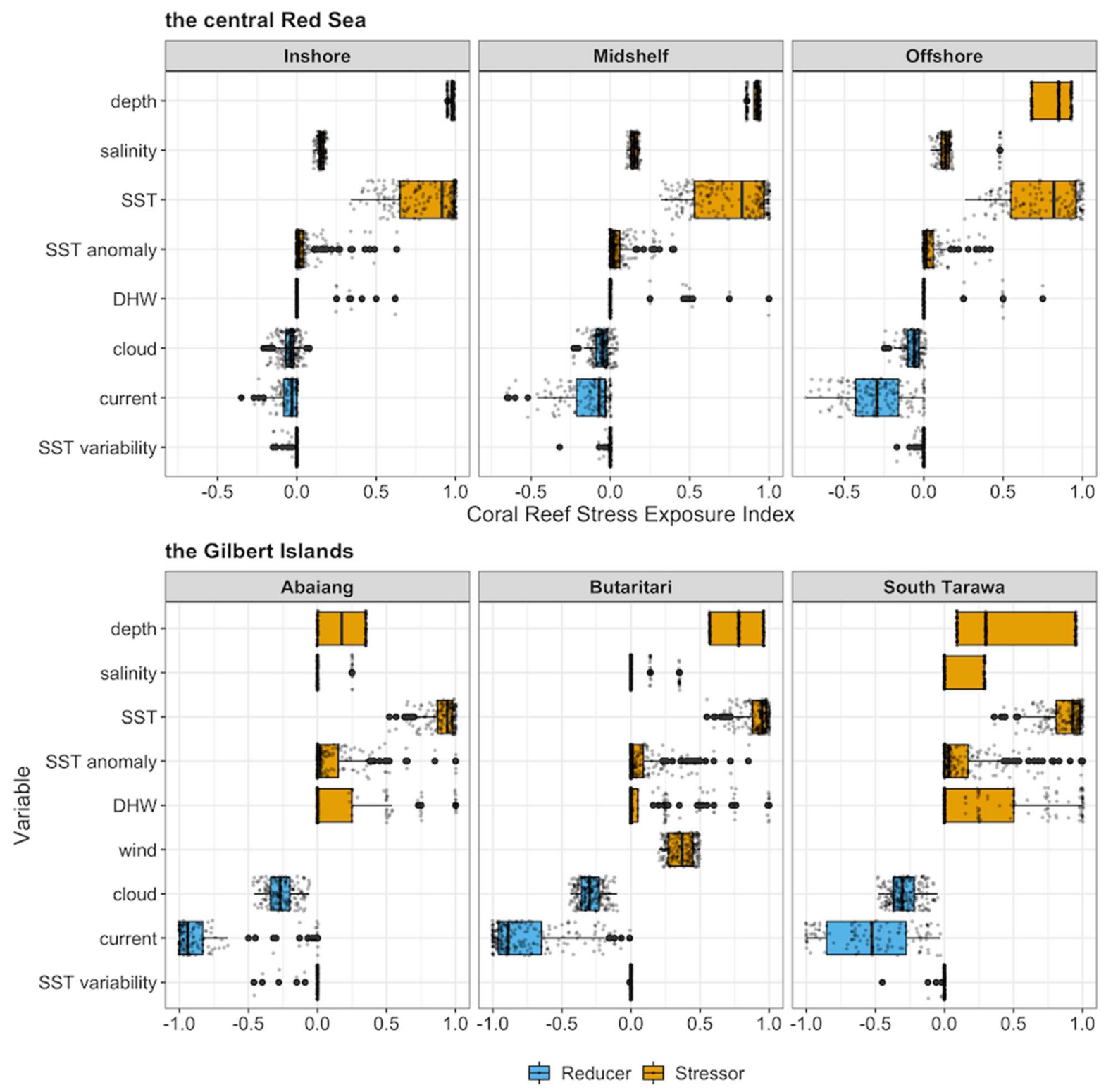

Figure 10. Box plots of the distribution of variable SE scores between different sites in the Gilbert Islands and the central Red Sea. 


\section{Discussion}

The CSREI provides a widely applicable index for monitoring spatial and temporal change and long-term trends in stress on coral reefs at global scale. Due to the use of free and open data, the CRSEI has the potential to make monitoring coral reefs more accessible to researchers, conservationists and managers, particularly for remote locations, the code for which can be found at https://github.com/mjw-marine/Coral-Reef-Stress-Exposure-Index. The index may provide a benchmark with which to compare, and inform, management interventions, as well as highlighting regions that have high risk or low resilience to disturbance. Based on a review of the literature, this study identified a range of variables that impact coral reef health available from free and open sources, including depth, SST, current, wind, and cloud cover. Thresholds to indicate stressed and non-stressed reefs at a global scale, and at a regional scale for some variables in the Chagos Archipelago, were also determined. The CRSEI scores from 3157 different reefs were able to distinguish differences in stress between regions and showed that, as expected, stress was significantly higher in El Niño periods compared to non-El Niño periods. Hence, our results illustrate that CRSEI can be used to determine spatial and temporal variation in stress at a global scale. For our three detailed case study regions, PCA analysis indicated that depth, current, SST and SST anomaly accounted for the greatest contribution to the variance. The CRSEI supported temporal and spatial differences in stress exposure from known disturbances within three case study regions, in addition to identifying the potential drivers of inter- and intra-region differences in stress, namely depth, DHW, and SST anomaly.

Application of the CRSEI to three case study regions indicated that the CRSEI can detect temporal differences in periods of stress on reef ecosystems, such as during El Niño events, as well as detecting spatial and temporal differences between different reefs within the same region. In addition to forming a single mean score for identifying periods of stress, the CRSEI can be broken down into variable-specific SE scores, to investigate what may be driving a high, or low, CRSEI in a particular region. Size of the eigen values of variable SE scores in the PCA indicated there were disparities in the impacts different variables had on sites in the three regions. For example, depth explained a large amount of the variance among the three case study regions and was not correlated with the majority of other variables (Figure 7). Sites within the same region tended, for the most part, to be clustered, indicating that there is regional variation in how variables cause stress on coral reef ecosystems. However, there can be variation within each region in the impact of different stress variables to the CRSEI (Figure 7, 9, 10). Our results show that the CRSEI has the potential to investigate both inter-, and intra-, regional differences in drivers of coral stress. The CRSEI can, therefore, be used to investigate what might be driving short term changes in coral reef ecosystems, as well as investigating long term drivers of stress, both within and between different regions. Therefore, the CRSEI provides an important index that can complement more detailed in situ sampling, as it can provide data on coral reef health more frequently and has the ability to discern the particular drivers of stress within a given location, rather than just the symptoms of stress.

Many of the current studies using remote sensing to evaluate coral reef stress and health, typically focus on one or two environmental variables, usually metrics of SST [49]. However, studies that utilise single environmental covariates, such as temperature, often perform worse at explaining ecological systems than those that use multiple variables [84]. The CRSEI captures multiple health stressors simultaneously and considers the interplay between variables rather than treating them as independent or as separate entities, and consequently could prove to be a useful tool for ecosystem management [20]. It provides a quantitative value which can be used to set targets and reference points for management options, as well as allowing users to either focus on the overall score or drill down into the contribution of individual variables. 
Coral degradation is ultimately caused by a complex of biological and environmental factors, in which there are currently significant knowledge gaps [38]. As such, our index cannot be used to directly quantify the health of coral reefs. Rather, it is a temporally explicit monitoring tool (i.e., to compare against various time periods from the same region) to evaluate relative changes in stress exposure on coral reef ecosystems. Most visual cues of stress only become apparent in advanced stages of coral reef stress, when coral reef health may already be compromised [85]. This index can be used to regularly monitor change in coral reef ecosystems, minimising the need for regular surveys which can be expensive and logistically challenging particularly in remote locations, as well as providing an early warning system that could lead to management intervention before severe damage occurs. In addition, by exploring historic datasets the CRSEI may allow researchers to determine the key stressors that lead up to large disturbance events. The CRSEI could provide valuable information on areas or regions that might most benefit from reef conservation strategies, such as no fishing zones or remote locations. It might also provide useful information about the best time for interventions to take place, such as coral transplantation, to maximise the chance of success. This index assesses, rather than models, current and future stress conditions, and as such, has no predictive power [86]. However, it may play a role in the simulation of future outcomes under different climate projection scenarios [86].

Interestingly, we saw no significant difference between CRSEI values which used global, or site specific, thresholds. This indicates that, despite a lack of regional information, the global threshold used here could be utilised across multiple different coral reefs ecosystems. However, these comparisons were just within a single region. Although all a priori selected variables have been found to have an impact on coral stress across different reef populations, their exact level of impact is often region specific. As such, there are some important uncertainties and assumptions made in developing this index, which is true of many indices [87]. For example, the CRSEI for the central Red Sea showed no obvious peaks and a more a cyclical pattern. It may be that thresholds for this region are greatly different from the global thresholds, and as such, the CRSEI is not identifying any obvious periods of stress. In addition, some localised factors, such as depth and upwellings, may have polarising effects on the stress on reefs depending on the region $[80,88]$. The CRSEI was designed in such a manner that it can be easily modified, and the index can be changed by altering threshold values or by adding and removing other known coral stressors. For example, in this study current was designated as a reducer, as increased current has been shown to reduce stress and bleaching on coral reefs $[32,89,90]$. However, in some coral reef regions, such as the South China Sea, and areas of the Greater Barrier Reef, low currents can exacerbate stress [91,92]. As reefs in different regions may have contrary responses to the same variable, regional and sitespecific thresholds should be used wherever possible. This will enable the index to be as accurate as possible and be a valuable tool for more focused management and conservation, However, where no specific variables are known, the use of these global thresholds still has merit.

In our case studies wind values were regularly not available for some sites and were removed when calculating undertaking the PCA analysis. One site lacked data on three variables and was removed from the analysis. In addition, five sites also lacked data on a single variable for the entire study period. There were removed for the PCA analysis but were kept for the CRSEI. This indicates that despite the global availability certain products and variables may not be available for coral reef ecosystems. This can be a particular problem close to coastlines [47,93]. However, only $14.7 \%(5 / 34)$ sites had data missing for a single variable throughout the entire study period, and a single site had data missing from multiple variables (Supplementary Table S2). This issue does have the potential to alter CRSEI values, particularly if those variables are important stressors to the reef system. However, as we use multiple different variables to calculate 
the CRSEI we do not see this as a serious problem and this issue may lessen in the future as more products become available on GEE.

In addition, the Automated Global Shallow Water Bathymetry Mapping method [52] has a maximum limitation of $20 \mathrm{~m}$. As it measures the light differences between blue and green bands, and no light differences are seen between blue and green light at $20 \mathrm{~m}$ and above, deep water areas are derived at $20 \mathrm{~m}$. As our threshold cut offs were at $20 \mathrm{~m}$ for depth and considering the low spatial resolution of the alternative in GEE, this was not considered a problem for this study. However, should stress monitoring using this index be attempted in ocean areas which are not shallow, on systems with deeper depth thresholds, an alternative depth product would be advised.

Variable data came from four different products; HYCOM: Water Temperature and Salinity; MODIS: Aqua; NOAA CDR; and HYCOM: Water Velocity, which are widely used for global scale analysis. Uncertainty values, with the exception of HYCOM: Water Velocity, were within the threshold values used for this study and were therefore sufficient to distinguish different levels of stress (Supplementary Table S1). Uncertainty estimates for HYCOM Water Velocity were only available from a study that examined uncertainty at a single point in time in a highly chaotic area, unrepresentative of many coral reef regions. As a result of this, and the fact that the CRSEI uses velocity values that are averaged over a month, we would expect uncertainty to be significantly lower than reported [94].

The accuracy for each variable and product may vary depending on region. As such, to improve the accuracy of the CRSEI per study region, regional uncertainty data could be integrated into the index. The accuracy of products may lead to potential issues with the score, particularly if the accuracy/error estimates are particularly large for a specific region. However, the effect of using multiple variables, and the fact that CRSEI values are developed on a linear, not categorial, scale should minimise this. In addition, this index is not meant to be used, as a definitive indicator of stress, but an inference method in lieu of more accurate, in situ, stress measurements which can be financially and logistically difficult to undertake on a regular basis. Despite these potential limitations, the findings here suggest that the CRSEI is an informative index, in that it shows intra- and inter regional differences, and supports previous results of the drivers of these differences at our three case study regions.

To increase the accuracy of the CRSEI further, and to aid the issue of unknown sitespecific thresholds, an information theoretic approach could be utilised to select and weight variables correctly for a given region. Multi-model inference has been extensively used to investigate drivers of disease ecology and health across multiple systems [95-97]. Should appropriate data be available, future research may generate a global model with live coral cover (or another stress validation metric) as the response variable, and a priori selected environmental stressors to reefs as explanatory variables. Model averaging would further improve index accuracy by weighting and selecting the most important variables and interactions to be included in the final CRSEI for each reef for each region of interest. However, this quantitative method requires extensive time series data of coral cover (or other metrics of coral stress), which, due to fiscal and logistical issues, is not always available. This approach was considered for this study but sufficient long term in situ data to train the model could not be identified.

Several variables known to have an impact on coral cover $(\mathrm{pH}, \mathrm{UV}$, chlorophyll- $a$ and turbidity) [98-100], were not included due to a lack of suitable products in GEE. pH and UV were not available in GEE, nor were there any appropriate proxies available. In addition, current chlorophyll- $a$ and turbidity products, such as POC, in GEE have low accuracy in shallow coastal areas [101-103]. There are algorithms for the detection of chlorophyll- $a$ and turbidity in shallow waters [104,105], but these were not sensitive enough to the levels that influence coral and not specific to coral regions, and, as such, accuracy would have been uncertain in the clear and shallow waters typical of coral reefs. In addition, integration and testing of these algorithms into Google Earth Engine 
was outside the scope of this study. In future, further development of these products, and their integration into GEE, would improve the accuracy of the CRSEI, and provide a better understanding of the stress coral reefs are facing.

The CRSEI is made up from data from abiotic stressors. Biotic and anthropogenic impacts, such as fishing pressure and community composition, have not been integrated. Further development of this index would involve integrating anthropogenic stressors into the metric, particularly for those reefs close to coastal communities. There are several products available in Google Earth Engine that could be integrated to develop this index further. Global Fishing Watch (https://globalfishingwatch.org/) uses ship automatic identification system (AIS) to track global fishing activity, freely available for public and research purposes [106,107]. Data on daily fishing and vessel hours is available on Google Earth Engine for analysis (https://developers.google.com/earth-engine/datasets/catalog/GFW GFF V1 fishing hours). Remote sensing of night time lights has also been shown to be a good proxy for estimating human population [108], and night time light data from the Suomi NPP VIIRS sensor [109] is also available from Google Earth Engine (https://developers.google.com/earth-engine/datasets/cata-

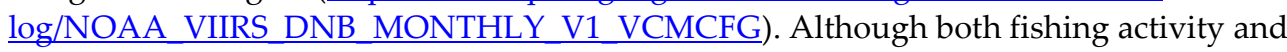
proximity to human populations have been shown to impact coral reef health [110,111], conclusions are not definitive [112]. As such, specific thresholds for fishing effort, distance from human population, or population density, are not currently available but might, in the future, be integrated into the index to provide a better estimate of stress exposure on global reef ecosystems.

Ideally, the CRSEI would be validated against metrics of coral stress, such as changes in live coral cover. However, due to financial and logistic costs, long, recurring (e.g., monthly) time series data of these metrics is rarely available $[19,113]$. In addition, coral reef response to stress is highly variable [32,114,115], and, even when present, there may be significant time lags in response, which may mean responses to altered environmental conditions are not always obvious, particularly with the often infrequent and/or irregular survey efforts for monitoring. However, validating the index against a regular time series of different in situ metrics of coral reef stress, for example live coral cover loss, three-dimensional complexity or recent mortality and algal growth, across different regions, would be an interesting next step for the future development of the CRSEI. In lieu of this, direct comparisons to other available stress indices, such as SST anomalies and trends, such as data from NOAA coral reef watch, could be undertaken in the future.

Established in 2010, Google is a relatively novel platform for providing satellite remote sensing data [51]. However, publications using this platform have gained pace in recent years, and it has been used across a range of varied applications [116], indicating the increased use and utility of this platform. It does, however, require some knowledge of either JavaScript or Python coding languages, as well knowledge of GEEs inbuilt functions [117]. The CRSEI has been designed for researchers to be able to adapt the index and the GEE code to their own applications, for example inputting site-specific thresholds for a more locally-specific index. However, the development of the GEE app [83] presented here also enables accessible user interface so that interested parties can utilise the CRSEI without any prior expertise off GEE or JavaScript.

\section{Conclusions}

Satellite remote sensing of the oceans has now developed sufficiently to enable the detection of multiple environmental variables with increasing accuracy from free and open sources. As such, satellite remote sensing is an important tool for researchers, conservationists, and managers. With the continued decline and degradation of the world's 
coral reefs, monitoring and management of these valuable ecosystems is vital. Due to their value and vulnerability, coral reefs are an important indicator for assessing how the marine environment is responding to climate change [21]. GEE is able to provide global products for multiple environmental stressors of coral reef populations. Here, we aggregated these stressors to calculate a Coral Reef Stress Exposure Index and provide a quantitative, transparent, and scalable measure for monitoring stress on coral reef ecosystems worldwide. We demonstrate the utility of this approach by mapping the CRSEI across 3157 reefs globally, as well as investigating the temporal trends in CRSEI from coral reef ecosystems at three well-documented sites in the Indian and Pacific oceans and the Red Sea. We propose the CRSEI as a versatile index that can provide regular global estimates of coral stressors, assisting in situ monitoring and reducing the financial and logistical burden, in some instances, of field monitoring techniques. The CRSEI, which is freely available through both a user-friendly app (https://mjw1280.users.earthengine.app/view/coral-reef-stress-exposure-index) and a GitHub code repository (https:/github.com/mjw-marine/Coral-Reef-Stress-Exposure-Index). will make monitoring and studying coral reef change more accessible for NGOs, managers, and researchers, and thus, is a potentially useful application for investigating threats to reef ecosystems into the future.

Supplementary Materials: The following are available online at www.mdpi.com/xxx/s1, Table S1: Accuracy and uncertainty of environmental variables from GG products used for the CRSEI, Table S2: Region, sites and reef names used for calculating Coral Reef Stress Exposure Score (CRSEI)., Table S3: Variables used for the assessment of coral reef stress, Table S4: Summary statistics for CRSEI scores per region by non-El Niño period (April 2012) and strong El Niño period (April 2016), Figure S1: Scree plot of PCA of CRSEI stress variables, Figure S2: Comparison of CRSEI scores using global and local thresholds for the Chagos Archipelago.

Author Contributions: Michael J. Williamson: Conceptualization; Data curation; Formal analysis; Methodology; Visualization; Writing - original draft; Writing - review \& editing. Emma J. Tebbs: Conceptualization; Methodology; Supervision; Writing - review \& editing. Henry J. Thompson: Software; Writing - review \& editing. Terrence P. Dawson: Supervision; Writing - review \& editing. Catherine E. I. Head: Conceptualization; Writing - review \& editing. David M. P. Jacoby: Supervision, Writing - review \& editing.

Funding: This work was supported by the Natural Environment Research Council (Grant No. NE/L002485/1) to MJW, as part of the London NERC Doctoral Training Partnership. Funding to DMPJ was provided by the Bertarelli Foundation and contributed to the Bertarelli Programme in Marine Science and by Research England.

Data Availability Statement: The code for the CRSEI written in JavaScript GEE API can be found at https://github.com/mjw-marine/Coral-Reef-Stress-Exposure-Index. All data used for analyses will be uploaded to Dryad (https://datadryad.org/stash/) on acceptance.

Acknowledgments: We would also like to thank Martin Birks for his help optimising the final CRSEI code in the Google Earth Engine API.

Conflicts of Interest: The authors declare no conflict of interest. The funders had no role in the design of the study; in the collection, analyses, or interpretation of data; in the writing of the manuscript, or in the decision to publish the results. 


\section{References}

1. Scheffer, M.; Carpenter, S.; Foley, J.A.; Folke, C.; Walker, B. Catastrophic shifts in ecosystems. Nature 2001, 413, 591, doi:10.1038/35098000.

2. Jones, G.P.; McCormick, M.I.; Srinivasan, M.; Eagle, J.V. Coral decline threatens fish biodiversity in marine reserves. Proc. Natl. Acad. Sci. U. S. A 2004, 101, 8251-8253, doi:10.1073/pnas.0401277101.

3. Sala, E.; Knowlton, N. Global Marine Biodiversity Trends. Annu. Rev. Environ. Resour. 2006, 31, 93-122, doi:10.1146/annurev.energy.31.020105.100235.

4. Moberg, F.; Folke, C. Ecological goods and services of coral reef ecosystems. Ecol. Econ. 1999, 29, 215-233, doi:10.1016/S09218009(99)00009-9.

5. Spalding, M.; Burke, L.; Wood, S.A.; Ashpole, J.; Hutchison, J.; zu Ermgassen, P. Mapping the global value and distribution of coral reef tourism. Mar. Policy 2017, 82, 104-113, doi:10.1016/j.marpol.2017.05.014.

6. Costanza, R.; d'Arge, R.; de Groot, R.; Farber, S.; Grasso, M.; Hannon, B.; Limburg, K.; Naeem, S.; O'Neill, R.V.; Paruelo, J.; et al. The value of the world's ecosystem services and natural capital. Nature 1997, 387, 253-260, doi:10.1038/387253a0.

7. Hughes, T.P.; Baird, A.H.; Bellwood, D.R.; Card, M.; Connolly, S.R.; Folke, C.; Grosberg, R.; Hoegh-Guldberg, O.; Jackson, J.B.C.; Kleypas, J.; et al. Climate change, human impacts, and the resilience of coral reefs. Science 2003, 301, 929, doi:10.1126/science.1085046.

8. Xu, J.; Zhao, D. Review of coral reef ecosystem remote sensing. Acta Ecol. Sin. 2014, 34, 19-25, doi:10.1016/j.chnaes.2013.11.003.

9. Burke, L.; Reytar, K.; Spalding, M.; Perry, A. Reefs at risk revisited; World Resources Institute,The Nature Conservancy, WorldFish Center, International Coral Reef Action Network, UNEP World Conservation Monitoring Centre and Global Coral Reef Monitoring Network: Washington, D.C., 2011.

10. Wilkinson, C.; Souter, D. Status of Caribbean coral reefs after bleaching and hurricanes in 2005; Global Coral Reef Monitoring Network, and Reef and Rainforest Research Centre: Townsville, QLD, 2008; p. 152.

11. Harvell, C.D.; Kim, K.; Burkholder, J.M.; Colwell, R.R.; Epstein, P.R.; Grimes, D.J.; Hofmann, E.E.; Lipp, E.K.; Osterhaus, A.D.M.E.; Overstreet, R.M.; et al. Emerging marine diseases--climate links and anthropogenic factors. Science 1999, 285, 1505, doi:10.1126/science.285.5433.1505.

12. Oliver, J.K.; Berkelmans, R.; Eakin, C.M. Coral bleaching in space and time. In Coral bleaching: patterns, processes, causes and consequences, van Oppen, M.J.H., Lough, J.M., Eds.; Springer International Publishing: Cham, 2018; pp. 27-49.

13. Fabricius, K.E.; De'ath, G.; Puotinen, M.L.; Done, T.; Cooper, T.F.; Burgess, S.C. Disturbance gradients on inshore and offshore coral reefs caused by a severe tropical cyclone. Limnol. Oceanogr. 2008, 53, 690-704, doi:10.4319/lo.2008.53.2.0690.

14. Eakin, C.M.; Sweatman, H.P.A.; Brainard, R.E. The 2014-2017 global-scale coral bleaching event: insights and impacts. Coral Reefs 2019, 38, 539-545, doi:10.1007/s00338-019-01844-2.

15. De'ath, G.; Fabricius, K.E.; Sweatman, H.; Puotinen, M. The 27-year decline of coral cover on the Great Barrier Reef and its causes. Proc. Natl. Acad. Sci. U.S.A. 2012, 109, 17995-17999, doi:10.1073/pnas.1208909109.

16. Bruno, J.F.; Selig, E.R. Regional decline of coral cover in the Indo-Pacific: Timing, extent, and subregional comparisons. PLoS ONE 2007, 2, e711, doi:10.1371/journal.pone.0000711.

17. Bellwood, D.R.; Pratchett, M.S.; Morrison, T.H.; Gurney, G.G.; Hughes, T.P.; Álvarez-Romero, J.G.; Day, J.C.; Grantham, R.; Grech, A.; Hoey, A.S.; et al. Coral reef conservation in the Anthropocene: confronting spatial mismatches and prioritizing functions. Biol. Conserv. 2019, 236, 604-615, doi:10.1016/j.biocon.2019.05.056.

18. Flower, J.; Ortiz, J.C.; Chollett, I.; Abdullah, S.; Castro-Sanguino, C.; Hock, K.; Lam, V.; Mumby, P.J. Interpreting coral reef monitoring data: a guide for improved management decisions. Ecol. Indic. 2017, 72, 848-869, doi:10.1016/j.ecolind.2016.09.003. 
19. Hedley, D.J.; Roelfsema, M.C.; Chollett, I.; Harborne, R.A.; Heron, F.S.; Weeks, S.; Skirving, J.W.; Strong, E.A.; Eakin, M.C.; Christensen, R.T.; et al. Remote sensing of coral reefs for monitoring and management: a review. Remote Sens. 2016, 8 , doi:10.3390/rs8020118.

20. Longo, C.S.; Frazier, M.; Doney, S.C.; Rheuban, J.E.; Humberstone, J.M.; Halpern, B.S. Using the Ocean Health Index to identify opportunities and challenges to improving Southern Ocean ecosystem health. Front. Mar. Sci. 2017, 4, doi:10.3389/fmars.2017.00020.

21. Obura, D.O.; Aeby, G.; Amornthammarong, N.; Appeltans, W.; Bax, N.; Bishop, J.; Brainard, R.E.; Chan, S.; Fletcher, P.; Gordon, T.A.C.; et al. Coral reef monitoring, reef assessment technologies, and ecosystem-based management. Front. Mar. Sci. 2019, 6, doi:10.3389/fmars.2019.00580.

22. Hedley, J.D.; Roelfsema, C.; Brando, V.; Giardino, C.; Kutser, T.; Phinn, S.; Mumby, P.J.; Barrilero, O.; Laporte, J.; Koetz, B. Coral reef applications of Sentinel-2: coverage, characteristics, bathymetry and benthic mapping with comparison to Landsat 8 . Remote. Sens. Environ. 2018, 216, 598-614, doi:10.1016/j.rse.2018.07.014.

23. Harvell, D.; Jordán-Dahlgren, E.; Merkel, S.; Rosenberg, E.; Raymundo, L.; Smith, G.; Weil, E.; Willis, B. Coral disease, environmental drivers, and the balance between coral and microbial associates. Oceanography 2007, 20, 172-195.

24. Head, C.E.I.; Bayley, D.T.I.; Rowlands, G.; Roche, R.C.; Tickler, D.M.; Rogers, A.D.; Koldewey, H.; Turner, J.R.; Andradi-Brown, D.A. Coral bleaching impacts from back-to-back 2015-2016 thermal anomalies in the remote central Indian Ocean. Coral Reefs 2019, doi:10.1007/s00338-019-01821-9.

25. Ban, S.S.; Graham, N.A.J.; Connolly, S.R. Evidence for multiple stressor interactions and effects on coral reefs. Glob. Change. Biol. 2014, 20, 681-697, doi:10.1111/gcb.12453.

26. Brandt, M.E.; Smith, T.B.; Correa, A.M.S.; Vega-Thurber, R. Disturbance driven colony fragmentation as a driver of a coral disease outbreak. PLoS ONE 2013, 8, e57164, doi:10.1371/journal.pone.0057164.

27. Hoegh-Guldberg, O. Climate change, coral bleaching and the future of the world's coral reefs. Mar. Freshw. Res. 1999, 50, 839866, doi:10.1071/MF99078.

28. Kathryn, P.S.; James, W.P.; Cecilia, T. Disease and immunity in Caribbean and Indo-Pacific zooxanthellate corals. Mar. Ecol. Prog. Ser. 2004, 266, 273-302.

29. Graham, N.A.J.; Jennings, S.; MacNeil, M.A.; Mouillot, D.; Wilson, S.K. Predicting climate-driven regime shifts versus rebound potential in coral reefs. Nature 2015, 518, 94, doi:10.1038/nature14140.

30. Mumby, P.; Chisholm, J.; Edwards, A.; Clark, C.; Roark, E.; Andrefouet, S.; Jaubert, J. Unprecedented bleaching-induced mortality in Porites spp. at Rangiroa Atoll, French Polynesia. Mar. Biol. 2001, 139, 183-189, doi:10.1007/s002270100575.

31. Lirman, D.; Manzello, D. Patterns of resistance and resilience of the stress-tolerant coral Siderastrea radians (Pallas) to sub-optimal salinity and sediment burial. J. Exp. Mar. Biol. Ecol. 2009, 369, 72-77, doi:10.1016/j.jembe.2008.10.024.

32. West, J.M.; Salm, R.V. Resistance and resilience to coral bleaching: implications for coral reef conservation and management. Conserv. Biol. 2003, 17, 956-967, doi:10.1046/j.1523-1739.2003.02055.x.

33. Goergen, E.A.; Moulding, A.L.; Walker, B.K.; Gilliam, D.S. Identifying causes of temporal changes in Acropora cervicornis populations and the potential for recovery. Front. Mar. Sci. 2019, 6, doi:10.3389/fmars.2019.00036.

34. Ellis, J.I.; Jamil, T.; Anlauf, H.; Coker, D.J.; Curdia, J.; Hewitt, J.; Jones, B.H.; Krokos, G.; Kürten, B.; Hariprasad, D.; et al. Multiple stressor effects on coral reef ecosystems. Glob. Change. Biol. 2019, 25, 4131-4146, doi:10.1111/gcb.14819.

35. Ormerod, S.J.; Dobson, M.; Hildrew, A.G.; Townsend, C.R. Multiple stressors in freshwater ecosystems. Freshw. Biol 2010, 55, 14, doi:10.1111/j.1365-2427.2009.02395.x.

36. Su, M.; Fath, B.D.; Yang, Z. Urban ecosystem health assessment: a review. Sci. Total. Environ 2010, 408, 2425-2434, doi:10.1016/j.scitotenv.2010.03.009. 
37. Rombouts, I.; Beaugrand, G.; Artigas, L.F.; Dauvin, J.C.; Gevaert, F.; Goberville, E.; Kopp, D.; Lefebvre, S.; Luczak, C.; Spilmont, N.; et al. Evaluating marine ecosystem health: case studies of indicators using direct observations and modelling methods. Ecol. Indic. 2013, 24, 353-365, doi:10.1016/j.ecolind.2012.07.001.

38. Suggett, D.J.; Smith, D.J. Coral bleaching patterns are the outcome of complex biological and environmental networking. Glob. Change. Biol. 2019, 26, 68-79, doi:10.1111/gcb.14871.

39. Bunn, S.E.; Abal, E.G.; Smith, M.J.; Choy, S.C.; Fellows, C.S.; Harch, B.D.; Kennard, M.J.; Sheldon, F. Integration of science and monitoring of river ecosystem health to guide investments in catchment protection and rehabilitation. Freshw. Biol 2010, 55, 223240, doi:10.1111/j.1365-2427.2009.02375.x.

40. Sheldon, F.; Peterson, E.E.; Boone, E.L.; Sippel, S.; Bunn, S.E.; Harch, B.D. Identifying the spatial scale of land use that most strongly influences overall river ecosystem health score. Ecol. Appl. 2012, 22, 2188-2203, doi:10.1890/11-1792.1.

41. Williams, M.; Longstaff, B.; Buchanan, C.; Llansó, R.; Dennison, W. Development and evaluation of a spatially-explicit index of Chesapeake Bay health. Mar. Pollut. Bull. 2009, 59, 14-25, doi:10.1016/j.marpolbul.2008.11.018.

42. Robertson, B.P.; Savage, C.; Gardner, J.P.A.; Robertson, B.M.; Stevens, L.M. Optimising a widely-used coastal health index through quantitative ecological group classifications and associated thresholds. Ecol. Indic. 2016, 69, 595-605, doi:10.1016/j.ecolind.2016.04.003.

43. Elfes, C.T.; Longo, C.; Halpern, B.S.; Hardy, D.; Scarborough, C.; Best, B.D.; Pinheiro, T.; Dutra, G.F. A regional-scale Ocean Health Index for Brazil. PLOS ONE 2014, 9, e92589-e92589, doi:10.1371/journal.pone.0092589.

44. Kachelriess, D.; Wegmann, M.; Gollock, M.; Pettorelli, N. The application of remote sensing for marine protected area management. Ecol. Indic. 2014, 36, 169-177, doi:10.1016/j.ecolind.2013.07.003.

45. Palacios, D.M.; Bograd, S.J.; Foley, D.G.; Schwing, F.B. Oceanographic characteristics of biological hot spots in the North Pacific: a remote sensing perspective. Deep Sea Res. Part II Top. Stud. Oceanogr. 2006, 53, 250-269, doi:10.1016/j.dsr2.2006.03.004.

46. Kuenzer, C.; Bluemel, A.; Gebhardt, S.; Quoc, T.V.; Dech, S. Remote Sensing of mangrove ecosystems: a review. Remote Sens. 2011, 3, 878, doi:10.3390/rs3050878.

47. Malthus, T.J.; Mumby, P.J. Remote sensing of the coastal zone: an overview and priorities for future research. Int. J. Remote Sens. 2003, 24, 2805-2815, doi:10.1080/0143116031000066954.

48. Skirving, W.; Marsh, B.; De La Cour, J.; Liu, G.; Harris, A.; Maturi, E.; Geiger, E.; Eakin, C.M. CoralTemp and the Coral Reef Watch Coral Bleaching Heat Stress Product Suite version 3.1. Remote Sens. 2020, 12, 3856, doi:10.3390/rs12233856.

49. Eakin, C.M.; Lough, J.M.; Heron, S.F. Climate variability and change: monitoring data and evidence for increased coral bleaching stress. In Coral Bleaching: Patterns, Processes, Causes and Consequences, van Oppen, M.J.H., Lough, J.M., Eds.; Springer Berlin Heidelberg: Berlin, Heidelberg, 2009; pp. 41-67.

50. Maina, J.; McClanahan, T.R.; Venus, V.; Ateweberhan, M.; Madin, J. Global gradients of coral exposure to environmental stresses and implications for local management. PLOS ONE 2011, 6, e23064, doi:10.1371/journal.pone.0023064.

51. Gorelick, N.; Hancher, M.; Dixon, M.; Ilyushchenko, S.; Thau, D.; Moore, R. Google Earth Engine: planetary-scale geospatial analysis for everyone. Remote. Sens. Environ. 2017, 202, 18-27, doi:10.1016/j.rse.2017.06.031.

52. Li, J.; Knapp, D.E.; Lyons, M.; Roelfsema, C.; Phinn, S.; Schill, S.R.; Asner, G.P. Automated global shallow water bathymetry mapping using Google Earth Engine. Remote Sens. 2021, 13, 1469, doi:10.3390/rs13081469.

53. Maina, J.; Venus, V.; McClanahan, T.R.; Ateweberhan, M. Modelling susceptibility of coral reefs to environmental stress using remote sensing data and GIS models. Ecol. Modell. 2008, 212, 180-199, doi:10.1016/j.ecolmodel.2007.10.033.

54. Wagner, D.E.; Kramer, P.; van Woesik, R. Species composition, habitat, and water quality influence coral bleaching in southern Florida. Mar. Ecol. Prog. Ser. 2010, 408, 65-78, doi:10.3354/meps08584.

55. Kayanne, H. Validation of degree heating weeks as a coral bleaching index in the northwestern Pacific. Coral Reefs 2017, 36, 6370, doi:10.1007/s00338-016-1524-y. 
56. Li, X.; Huang, H.; Lian, J.; Huang, L.; Dong, J. Effects of the multiple stressors high temperature and reduced salinity on the photosynthesis of the hermatypic coral Galaxea fascicularis. Acta Ecol. Sin. 2009, 29, 155-159, doi:10.1016/j.chnaes.2009.07.002.

57. Heidinger, A.K.; Foster, M.J.; Walther, A.; Zhao, X.; NOAA CDR Program. NOAA Climate Data Record (CDR) of Cloud Properties from AVHRR Pathfinder Atmospheres - Extended (PATMOS-x), Version 5.3. NOAA National Centers for Environmental Information. 2014, doi:10.7289/V5348HCK.

58. Cummings, J.A.; Smedstad, O.M. Variational data assimilation for the global ocean. In Data assimilation for atmospheric, oceanic and hydrologic applications (Vol. II), Park, S.K., Xu, L., Eds.; Springer Berlin Heidelberg: Berlin, Heidelberg, 2013 ; pp. $303-343$.

59. NASA Goddard Space Flight Center; Ocean Ecology Laboratory; Group, O.B.P. Moderate-resolution Imaging Spectroradiometer (MODIS) Aqua Remote-Sensing Reflectance Data. 2018 Reprocessing. NASA OB.DAAC, Greenbelt, MD, USA doi:10.5067/AQUA/MODIS/L3M/RRS/2018.

60. Clayson, C.A.; Brown, J.; NOAA CDR Program. NOAA Climate Data Record Ocean Surface Bundle (OSB) Climate Data Record (CDR) of Ocean Near Surface Atmospheric Properties, Version 2. NOAA National Center for Environmental Information 2016, doi:10.7289/V55T3HH0.

61. Tebbs, E.J.; Avery, S.T.; Chadwick, M.A. Satellite remote sensing reveals impacts from dam-associated hydrological changes on chlorophyll-a in the world's largest desert lake. River. Res. Appl 2020, 36, 211-222, doi:10.1002/rra.3574.

62. Hernandez, F.; Smith, G.; Baetens, K.; Cossarini, G.; Garcia-Hermosa, I.; Drevillon, M.; Maksymczuk, J.; Melet, A.; Regnier, C.; von Schuckman, K. Measuring performances, skill and accuracy in operational oceanography: new challenges and approaches. In New Frontiers in Operational Oceanography, Chassignet, E.P., Pascual, A., Tintorè, J., Verron, J., Eds.; GODAE OceanView: Tallahasse, FL, 2018; pp. 759-795.

63. Obura, D.; Grimsditch, G.; Marshall, P.; Setiasih, N.; Aeby, G.; McLeod, L.; Green, A.; Bellwood, D.; Choat, H.; Machano, H.; et al. Resilience assessment of coral reefs: assessment protocol for coral reefs, focusing on coral bleaching and thermal stress; 2831711517; IUCN: Gland, Switzerland, 2009.

64. Rowlands, G.; Purkis, S.; Riegl, B.; Metsamaa, L.; Bruckner, A.; Renaud, P. Satellite imaging coral reef resilience at regional scale. A case-study from Saudi Arabia. Mar. Pollut. Bull. 2012, 64, 1222-1237, doi:10.1016/j.marpolbul.2012.03.003.

65. Röthig, T.; Ochsenkühn, M.A.; Roik, A.; van der Merwe, R.; Voolstra, C.R. Long-term salinity tolerance is accompanied by major restructuring of the coral bacterial microbiome. Mol. Ecol. 2016, 25, 1308-1323, doi:10.1111/mec.13567.

66. Guan, Y.; Hohn, S.; Merico, A. Suitable environmental ranges for potential coral reef habitats in the tropical ocean. PLoS ONE 2015, 10, e0128831, doi:10.1371/journal.pone.0128831.

67. Coles, S.L.; Jokiel, P.L. Effects of salinity on coral reefs. In Pollution in tropical aquatic systems, Connell, D.W., Hawker, D.W., Eds.; CRC Press: Boca Raton, FL, 1992; pp. 147-166.

68. R Core Team R: a language and environment for statistical computing, R Foundation for Statistical Computing: Vienna, Austria, 2020.

69. Claar, D.C.; Szostek, L.; McDevitt-Irwin, J.M.; Schanze, J.J.; Baum, J.K. Global patterns and impacts of El Niño events on coral reefs: a meta-analysis. PLoS ONE 2018, 13, e0190957, doi:10.1371/journal.pone.0190957.

70. Stone, L.; Rajagopalan, B.; Bhasin, H.; Loya, Y. Mass coral reef bleaching: a recent outcome of increased El Niño Activity? Ecol. Lett. 1999, 2, 325-330, doi:10.1046/j.1461-0248.1999.00092.x.

71. Bates, D.; Mächler, M.; Bolker, B.; Walker, S. Fitting linear mixed-effects models using lme4. J. Stat. Softw. 2014, 67, 1-48, doi:10.18637/jss.v067.i01.

72. Sheppard, C.; Sheppard, A.; Mogg, A.; Bayley, D.; Dempsey, A.; Roche, R.; Turner, J.; Purkis, S. Coral bleaching and mortality in the Chagos Archipelago to 2017. Atoll Res. Bull. 2017, 613, 1-25, doi:10.5479/si.0077-5630.613.

73. Carilli, J.; Donner, S.D.; Hartmann, A.C. Historical temperature variability affects coral response to heat stress. PLoS ONE 2012, 7, e34418, doi:10.1371/journal.pone.0034418. 
74. Donner, S.D.; Carilli, J. Resilience of Central Pacific reefs subject to frequent heat stress and human disturbance. Sci. Rep. 2019, 9, 3484, doi:10.1038/s41598-019-40150-3.

75. Furby, K.A.; Bouwmeester, J.; Berumen, M.L. Susceptibility of central Red Sea corals during a major bleaching event. Coral Reefs 2013, 32, 505-513, doi:10.1007/s00338-012-0998-5.

76. Monroe, A.A.; Ziegler, M.; Roik, A.; Röthig, T.; Hardenstine, R.S.; Emms, M.A.; Jensen, T.; Voolstra, C.R.; Berumen, M.L. In situ observations of coral bleaching in the central Saudi Arabian Red Sea during the 2015/2016 global coral bleaching event. PLoS ONE 2018, 13, e0195814, doi:10.1371/journal.pone.0195814.

77. Bridge, T.C.L.; Hoey, A.S.; Campbell, S.J.; Muttaqin, E.; Rudi, E.; Fadli, N.; Baird, A.H. Depth-dependent mortality of reef corals following a severe bleaching event: implications for thermal refuges and population recovery. F1000Res. 2013, 2, 187-187, doi:10.12688/f1000research.2-187.v3.

78. Lesser, M.P.; Stochaj, W.R.; Tapley, D.W.; Shick, J.M. Bleaching in coral reef anthozoans: effects of irradiance, ultraviolet radiation, and temperature on the activities of protective enzymes against active oxygen. Coral Reefs 1990, 8, 225-232, doi:10.1007/bf00265015.

79. Spencer, T.; Teleki, K.A.; Bradshaw, C.; Spalding, M.D. Coral bleaching in the southern Seychelles during the 1997-1998 Indian Ocean warm event. Mar. Pollut. Bull. 2000, 40, 569-586, doi:10.1016/S0025-326X(00)00026-6.

80. Chollett, I.; Mumby, P.J.; Cortés, J. Upwelling areas do not guarantee refuge for coral reefs in a warming ocean. Mar. Ecol. Prog. Ser. 2010, 416, 47-56, doi:10.3354/meps08775.

81. D'Croz, L.; Maté, J.L.; Oke, J.E. Responses to elevated sea water temperature and UV radiation in the coral Porites lobata from upwelling and non-upwelling environments on the Pacific coast of Panama. Bull. Mar. Sci. 2001, 69, $203-214$.

82. Fagerland, M.W. t-tests, non-parametric tests, and large studies-a paradox of statistical practice? BMC Med. Res. Methodol. 2012, 12, 78, doi:10.1186/1471-2288-12-78.

83. Tamiminia, H.; Salehi, B.; Mahdianpari, M.; Quackenbush, L.; Adeli, S.; Brisco, B. Google Earth Engine for geo-big data applications: a meta-analysis and systematic review. ISPRS J. Photogramm. Remote Sens. 2020, 164, 152-170, doi:10.1016/j.isprsjprs.2020.04.001.

84. McHenry, J.; Welch, H.; Lester, S.E.; Saba, V. Projecting marine species range shifts from only temperature can mask climate vulnerability. Glob. Change. Biol. 2019, 25, 4208-4221, doi:10.1111/gcb.14828.

85. Glasl, B.; Webster, N.S.; Bourne, D.G. Microbial indicators as a diagnostic tool for assessing water quality and climate stress in coral reef ecosystems. Mar. Biol. 2017, 164, 91, doi:10.1007/s00227-017-3097-x.

86. Halpern, B.S.; Longo, C.; Hardy, D.; McLeod, K.L.; Samhouri, J.F.; Katona, S.K.; Kleisner, K.; Lester, S.E.; O'Leary, J.; Ranelletti, M.; et al. An index to assess the health and benefits of the global ocean. Nature 2012, 488, 615-620, doi:10.1038/nature11397.

87. Lane, D.R.; Ready, R.C.; Buddemeier, R.W.; Martinich, J.A.; Shouse, K.C.; Wobus, C.W. Quantifying and valuing potential climate change impacts on coral reefs in the United States: comparison of two scenarios. PLoS ONE 2014, 8, e82579, doi:10.1371/journal.pone.0082579.

88. Muir, P.R.; Marshall, P.A.; Abdulla, A.; Aguirre, J.D. Species identity and depth predict bleaching severity in reef-building corals: shall the deep inherit the reef? Proc. R. Soc. B 2017, 284, 20171551, doi:10.1098/rspb.2017.1551.

89. Obura, D.O. Resilience and climate change: lessons from coral reefs and bleaching in the Western Indian Ocean. Estuar. Coast. Shelf. Sci. 2005, 63, 353-372, doi:10.1016/j.ecss.2004.11.010.

90. Page, C.E.; Leggat, W.; Heron, S.F.; Choukroun, S.M.; Lloyd, J.; Ainsworth, T.D. Seeking resistance in coral reef ecosystems: the interplay of biophysical factors and bleaching resistance under a changing climate. Bioessays 2019, 41, 1800226, doi:10.1002/bies.201800226.

91. DeCarlo, T.M.; Cohen, A.L.; Wong, G.T.F.; Davis, K.A.; Lohmann, P.; Soong, K. Mass coral mortality under local amplification of $2{ }^{\circ} \mathrm{C}$ ocean warming. Sci. Rep. 2017, 7, 44586, doi:10.1038/srep44586. 
92. DeCarlo, T.M.; Harrison, H.B. An enigmatic decoupling between heat stress and coral bleaching on the Great Barrier Reef. PeerJ 2019, 7, e7473, doi:10.7717/peerj.7473.

93. Cracknell, A.P. Remote sensing techniques in estuaries and coastal zones an update. Int. J. Remote Sens. 1999, 20, 485-496, doi:10.1080/014311699213280.

94. Savage, J.A.; Tokmakian, R.T.; Batteen, M.L. Assessment of the HYCOM velocity fields during Agulhas Return Current Cruise 2012. J. Oper. Oceanogr. 2015, 8, 11-24, doi:10.1080/1755876X.2015.1014637.

95. Gurevitz, J.M.; Ceballos, L.A.; Gaspe, M.S.; Alvarado-Otegui, J.A.; Enríquez, G.F.; Kitron, U.; Gürtler, R.E. Factors affecting infestation by Triatoma infestans in a rural area of the humid Chaco in Argentina: a multi-model inference approach. PLoS neglected tropical diseases 2011, 5, e1349-e1349, doi:10.1371/journal.pntd.0001349.

96. North, A.C.; Hodgson, D.J.; Price, S.J.; Griffiths, A.G.F. Anthropogenic and ecological drivers of amphibian disease (ranavirosis). PLoS ONE 2015, 10, e0127037-e0127037, doi:10.1371/journal.pone.0127037.

97. Plowright, R.K.; Sokolow, S.H.; Gorman, M.E.; Daszak, P.; Foley, J.E. Causal inference in disease ecology: investigating ecological drivers of disease emergence. Front. Ecol. Environ. 2008, 6, 420-429, doi:10.1890/070086.

98. Coelho, V.R.; Fenner, D.; Caruso, C.; Bayles, B.R.; Huang, Y.; Birkeland, C. Shading as a mitigation tool for coral bleaching in three common Indo-Pacific species. J. Exp. Mar. Biol. Ecol. 2017, 497, 152-163, doi:10.1016/j.jembe.2017.09.016.

99. Mason, R.A.B.; Skirving, W.J.; Dove, S.G. Integrating physiology with remote sensing to advance the prediction of coral bleaching events. Remote. Sens. Environ. 2020, 246, 111794, doi:10.1016/j.rse.2020.111794.

100. Sokolow, S. Effects of a changing climate on the dynamics of coral infectious disease: a review of the evidence. Dis. Aquat. Org. 2009, 87, 5-18, doi:10.3354/dao02099.

101. Reichstetter, M.; Fearns, P.R.C.S.; Weeks, S.J.; McKinna, L.I.W.; Roelfsema, C.; Furnas, M. Bottom reflectance in ocean color satellite remote sensing for coral reef environments. Remote Sens. 2015, 7, 16756-16777, doi:10.3390/rs71215852.

102. Le, C.; Hu, C.; Cannizzaro, J.; English, D.; Muller-Karger, F.; Lee, Z. Evaluation of chlorophyll-a remote sensing algorithms for an optically complex estuary. Remote. Sens. Environ. 2013, 129, 75-89, doi:10.1016/j.rse.2012.11.001.

103. Wattelez, G.; Dupouy, C.; Lefèvre, J.; Ouillon, S.; Fernandez, J.-M.; Juillot, F. Application of the support vector regression method for turbidity assessment with MODIS on a shallow coral reef lagoon (Voh-Koné-Pouembout, New Caledonia). Water 2017, 9, 737, doi:10.3390/w9100737.

104. Dogliotti, A.I.; Ruddick, K.G.; Nechad, B.; Doxaran, D.; Knaeps, E. A single algorithm to retrieve turbidity from remotely-sensed data in all coastal and estuarine waters. Remote. Sens. Environ. 2015, 156, 157-168, doi:10.1016/j.rse.2014.09.020.

105. Abbas, M.M.; Melesse, A.M.; Scinto, L.J.; Rehage, J.S. Satellite Estimation of chlorophyll-a using Moderate Resolution Imaging Spectroradiometer (MODIS) sensor in shallow coastal water bodies: validation and improvement. Water 2019, 11, 1621, doi:10.3390/w11081621.

106. Ruiz, J.; Caballero, I.; Navarro, G. Sensing the same fishing fleet with AIS and VIIRS: a seven-year assessment of squid jiggers in FAO Major Fishing Area 41. Remote Sens. 2020, 12, 32, doi:10.3390/rs12010032.

107. Kroodsma, D.A.; Mayorga, J.; Hochberg, T.; Miller, N.A.; Boerder, K.; Ferretti, F.; Wilson, A.; Bergman, B.; White, T.D.; Block, B.A.; et al. Tracking the global footprint of fisheries. Science 2018, 359, 904-908, doi:10.1126/science.aao5646.

108. Levin, N.; Zhang, Q. A global analysis of factors controlling VIIRS nighttime light levels from densely populated areas. Remote. Sens. Environ. 2017, 190, 366-382, doi:10.1016/j.rse.2017.01.006.

109. Elvidge, C.D.; Baugh, K.; Zhizhin, M.; Hsu, F.C.; Ghosh, T. VIIRS night-time lights. Int. J. Remote Sens. 2017, 38, 5860-5879, doi:10.1080/01431161.2017.1342050.

110. Smith, J.E.; Brainard, R.; Carter, A.; Grillo, S.; Edwards, C.; Harris, J.; Lewis, L.; Obura, D.; Rohwer, F.; Sala, E.; et al. Reevaluating the health of coral reef communities: baselines and evidence for human impacts across the central Pacific. Proc. $R$. Soc. B 2016, 283, 20151985, doi:doi:10.1098/rspb.2015.1985. 
111. Bruce, T.; Meirelles, P.M.; Garcia, G.; Paranhos, R.; Rezende, C.E.; de Moura, R.L.; Filho, R.-F.; Coni, E.O.C.; Vasconcelos, A.T.; Amado Filho, G.; et al. Abrolhos Bank reef health evaluated by means of water quality, microbial diversity, benthic cover, and fish biomass data. PLOS ONE 2012, 7, e36687, doi:10.1371/journal.pone.0036687.

112. Bruno, J.F.; Valdivia, A. Coral reef degradation is not correlated with local human population density. Sci. Rep. 2016, 6, 29778, doi:10.1038/srep29778.

113. Hamylton, S.M. Mapping coral reef environments: a review of historical methods, recent advances and future opportunities. Prog. Phys. Geogr. Earth Environ. 2017, 41, 803-833, doi:10.1177/0309133317744998.

114. Mumby, Peter J.; van Woesik, R. Consequences of ecological, evolutionary and biogeochemical uncertainty for coral reef responses to climatic stress. Curr. Biol. 2014, 24, R413-R423, doi:10.1016/j.cub.2014.04.029.

115. McClanahan, T.R.; Darling, E.S.; Maina, J.M.; Muthiga, N.A.; D agata, S.; Leblond, J.; Arthur, R.; Jupiter, S.D.; Wilson, S.K.; Mangubhai, S.; et al. Highly variable taxa-specific coral bleaching responses to thermal stresses. Mar. Ecol. Prog. Ser. 2020, 648, 135-151, doi:10.3354/meps13402.

116. Kumar, L.; Mutanga, O. Google Earth Engine applications since inception: usage, trends, and potential. Remote Sens. 2018, 10, 1509, doi:10.3390/rs10101509.

117. Williamson, M.J.; Tebbs, E.J.; Dawson, T.P.; Jacoby, D.M.P. Satellite remote sensing in shark and ray ecology, conservation and management. Front. Mar. Sci. 2019, 6, doi:10.3389/fmars.2019.00135. 